\title{
Activity Origin and Multifunctionality of Pt-Based Intermetallic Nanostructures for Efficient Electrocatalysis
}

Ho Young Kim,,$^{\dagger, \#}$ Jong Min Kim, ${ }^{\S, \#}$ Yoonhoo Ha,ll\# Jinwoo Woo, ${ }^{\dagger}$ Ayoung Byun, ${ }^{\S}$ Tae Joo Shin,,$^{\ddagger}$

Kang Hyun Park, ${ }^{\perp}$ Hu Young Jeong, ${ }^{*}+\grave{t}$ Hyungjun Kim,,${ }^{\prime}$ Jin Young Kim, ${ }^{*} \S$

and Sang Hoon Joo ${ }^{* \dagger}$

${ }^{\dagger}$ Department of Energy Engineering and School of Energy and Chemical Engineering, and

IUNIST Central Research Facilities, Ulsan National Institute of Science and Technology

(UNIST), 50 UNIST-gil, Ulsan 44919, Republic of Korea.

${ }^{\S}$ Center for Hydrogen and Fuel Cell Research, Korea Institute of Science and Technology (KIST),

5 Hwarangno 14-gil, Seoul 02792, Republic of Korea.

"Department of Chemistry, Korea Advanced Institute of Science and Technology (KAIST), 291

Daehak-Ro, Daejeon 34141, Republic of Korea.

${ }^{\perp}$ Department of Chemistry, Pusan National University, Busan, 46241, Republic of Korea.

\#These authors contributed equally to this work. 


\section{Table of Contents}

\section{Supporting Figures and Tables}

Figure S1. DFT optimized structures and total energies per formula unit of $D-\mathrm{Pt}_{3} \mathrm{Co}$ models.

Figure S2. All possible oxygen adsorption sites of the $D$-Pt ${ }_{3}$ Co surfaces.

Figure S3. All possible oxygen adsorption sites of the $O-\mathrm{Pt}_{3} \mathrm{Co}$ surfaces.

Figure S4. Four possible active sites of $O-\mathrm{Pt}_{3} \mathrm{Co}$ surfaces, having different Co subsurface coordinating environments.

Figure S5. Additional HAADF-STEM images and EDS elemental maps of $O-\mathrm{Pt}_{3} \mathrm{Co}$ NWs.

Figure S6. EELS line profile analysis of $O-\mathrm{Pt}_{3} \mathrm{Co} \mathrm{NWs}$.

Figure S7. Co $2 \mathrm{p}$ XPS and Co K-edge XANES spectra of $D-\mathrm{Pt}_{3} \mathrm{Co} \mathrm{NW}$ and $O-\mathrm{Pt}_{3} \mathrm{Co}$ NWs.

Figure S8. Pt $4 \mathrm{f}$ XPS and $\mathrm{Pt} \mathrm{L}_{3}$-edge XANES spectra of $D$-Pt ${ }_{3} \mathrm{Co} \mathrm{NWs}$ and $O-\mathrm{Pt}_{3} \mathrm{Co}$ NWs.

Figure S9. XRD patterns and TEM images of $\mathrm{Pt}_{3} \mathrm{Fe}$ NWs.

S12

Figure S10. XRD patterns and TEM images of $\mathrm{Pt}_{3} \mathrm{Co}$ Networks.

Figure S11. ECSAs of the catalysts measured by hydrogen underpotential deposition and $\mathrm{CO}$ stripping.

Figure S12. ORR Tafel plots of the catalysts.

Figure S13. ORR specific activities of the catalysts before and after the ORR catalyst ADT.

Figure S14. Electrocatalytic activities of Pt NWs.

Figure S15. Electrocatalytic properties of the catalysts before and after the ORR catalyst ADT.

Figure S16. Additional HAADF-STEM image of $O$-Pt $\mathrm{Pt}_{3}$ Co NWs after 30,000 cycles of ORR catalyst ADT.

Figure S17. TEM analyses of the catalysts before and after the ORR catalyst ADT.

Figure S18. Structural analyses of $O-\mathrm{Pt}_{3} \mathrm{Co} / \mathrm{C}$ catalyst.

Figure S19. Electrocatalytic properties of $O-\mathrm{Pt}_{3} \mathrm{Co} / \mathrm{C}$ before and after the ORR Catalyst ADT.

Figure S20. Electrocatalytic properties of $O-\mathrm{Pt}_{3} \mathrm{Co} / \mathrm{C}$ before and after the ORR Catalyst ADT. 
Figure S21. ORR specific activities of the catalysts before and after the ORR support ADT.

Figure S22. Electrocatalytic properties of $O-\mathrm{Pt}_{3} \mathrm{Co} / \mathrm{C}$ before and after the ORR support ADT.

Figure S23. HAADF-STEM and EDS elemental maps of $O-\mathrm{Pt}_{3} \mathrm{Co} \mathrm{NW}$ s after the ORR support ADT.

Figure S24. TEM analyses of the catalysts before and after the ORR support ADT.

S27

Figure S25. TEM analyses of the catalysts before and after the alkaline HER stability

S28 tests.

Figure S26. Electrocatalytic properties of the catalysts before and after the MOR ADT.

Figure S27. TEM analyses of the catalysts before and after the MOR ADT.

S30

Figure S28. Cross-sectional SEM images of MEAs for PEMFC single cells.

S31

Figure S29. PEMFC single cell performances of MEAs tested in RH 100\%, $\mathrm{O}_{2} 1.8$

S32 bar.

Figure S30. PEMFC single cell performances of MEAs tested in RH 50\%, air 1.8 bar.

Figure S31. PEMFC single cell performances of MEAs tested in RH 100\%, air 1.8 bar.

Table S1. Fitting results of the multiple linear regression model to predict DFTcalculated oxygen binding energies.

Table S2. $\Delta E_{\mathrm{O}}$ values calculated using the linear regression model, the population of distinct subsurface-coordinating-environments, and estimated specific activity enhancement at all possible active sites of the $D$ - $\mathrm{Pt}_{3} \mathrm{Co}$ surface. For comparison, $O$ $\mathrm{Pt}_{3} \mathrm{Co}$ cases are shown in parenthesis.

Table S3. Comparison of ORR activity parameters of $O-\mathrm{Pt}_{3} \mathrm{Co} \mathrm{NWs}$ with those of previously reported Pt-based free-standing catalysts. 


\section{Supporting Figures and Tables}

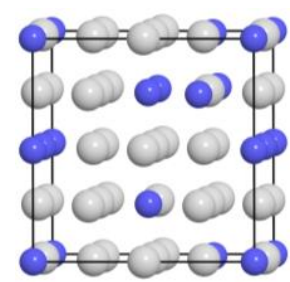

Random alloy 1 $-24.5055 \mathrm{eV} / \mathrm{f}$.u.

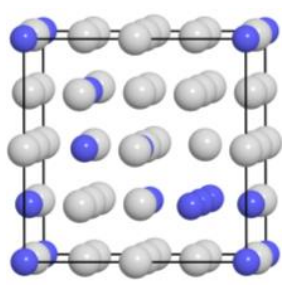

Random alloy 2 $-24.5041 \mathrm{eV} / \mathrm{f}$.u.

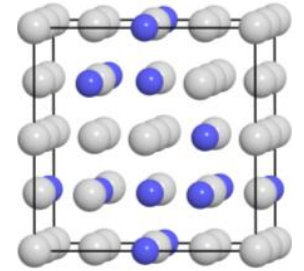

Random alloy 3 $-24.5003 \mathrm{eV} / \mathrm{f} . \mathrm{u}$.

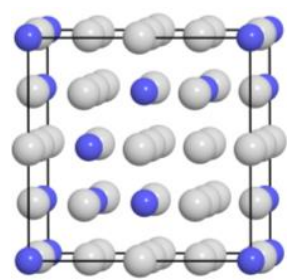

Random alloy 4 -24.4967 eV / f.u.

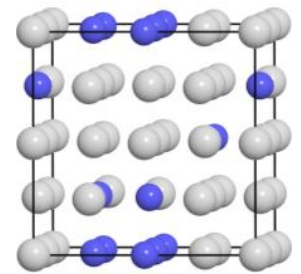

Random alloy 5 -24.4965 eV / f.u

Figure S1. DFT optimized structures and total energies per formula unit of $D-\mathrm{Pt}_{3} \mathrm{Co}$ models. Five disordered alloy $\mathrm{Pt}_{3} \mathrm{Co}\left(D-\mathrm{Pt}_{3} \mathrm{Co}\right)$ models were randomly generated. Random alloy 1 was calculated to be the most stable bulk structure among the five models, and was hence employed for the $D-\mathrm{Pt}_{3} \mathrm{Co}$ surface slab model. 

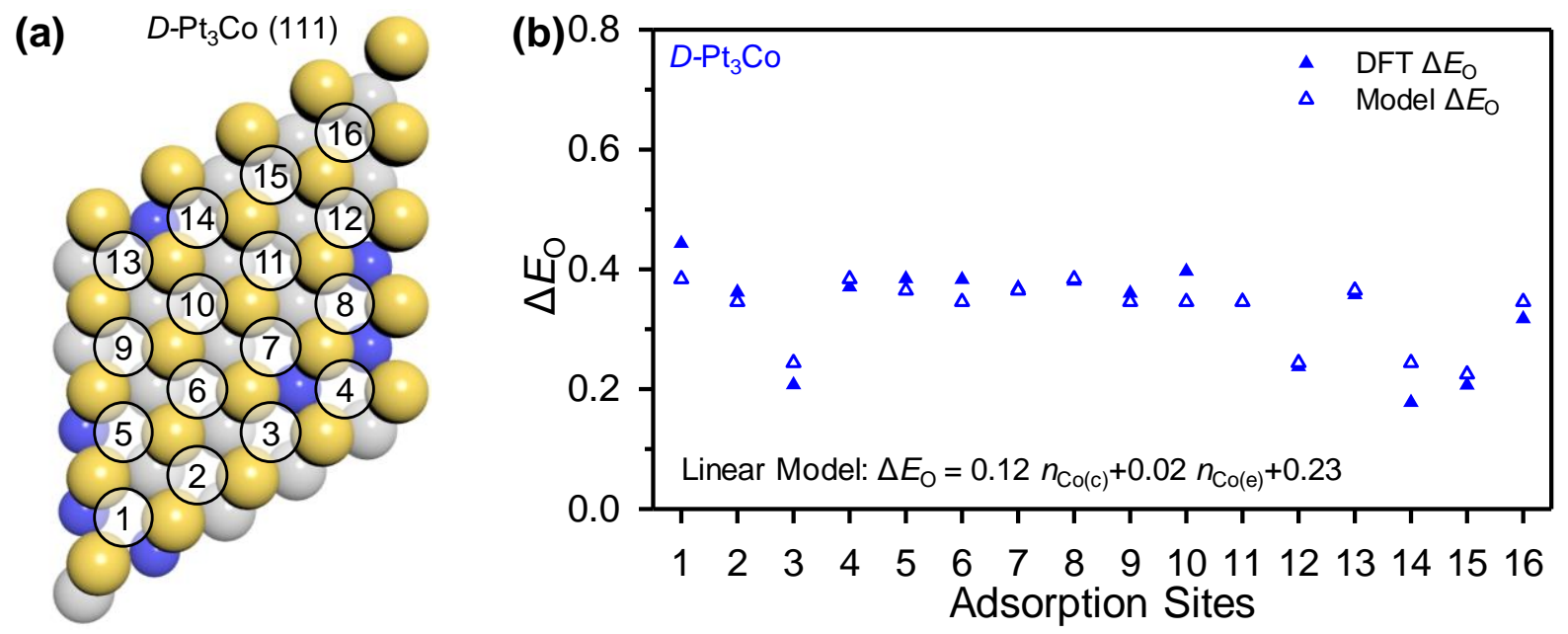

(c)

\begin{tabular}{c|cccccccccccccccc}
\hline sites & $\mathbf{1}$ & $\mathbf{2}$ & $\mathbf{3}$ & $\mathbf{4}$ & $\mathbf{5}$ & $\mathbf{6}$ & $\mathbf{7}$ & $\mathbf{8}$ & $\mathbf{9}$ & $\mathbf{1 0}$ & $\mathbf{1 1}$ & $\mathbf{1 2}$ & $\mathbf{1 3}$ & $\mathbf{1 4}$ & $\mathbf{1 5}$ & $\mathbf{1 6}$ \\
\hline $\begin{array}{c}\mathrm{DFT} \Delta E_{\mathrm{O}} \\
(\mathrm{eV})\end{array}$ & 0.44 & 0.36 & 0.21 & 0.37 & 0.38 & 0.38 & 0.37 & 0.38 & 0.36 & 0.40 & 0.35 & 0.24 & 0.36 & 0.18 & 0.21 & 0.32 \\
$\begin{array}{c}\text { Model } \Delta E_{\mathrm{O}} \\
(\mathrm{eV})\end{array}$ & 0.38 & 0.35 & 0.24 & 0.38 & 0.36 & 0.35 & 0.36 & 0.38 & 0.35 & 0.35 & 0.35 & 0.24 & 0.36 & 0.24 & 0.22 & 0.35 \\
$\begin{array}{c}\text { Coordination } \\
\left(\boldsymbol{n}_{\mathrm{Co}(\mathrm{c})}, n_{\mathrm{Co}(\mathrm{e})}\right)\end{array}$ & $(1,0)$ & $(1,2)$ & $(0,0)$ & $(1,1)$ & $(1,1)$ & $(1,2)$ & $(1,0)$ & $(1,0)$ & $(1,0)$ & $(1,2)$ & $(1,0)$ & $(0,1)$ & $(1,1)$ & $(0,1)$ & $(0,1)$ & $(1,0)$ \\
\hline
\end{tabular}

Figure S2. All possible oxygen adsorption sites of the $D-\mathrm{Pt}_{3} \mathrm{Co}$ surfaces. (a) All possible oxygen adsorption sites of the $D-\mathrm{Pt}_{3} \mathrm{Co}$ surface are indicated by circles. (b) Comparison between $\Delta E_{\mathrm{O}}$ values from DFT and those from the linear regression model $\left(\Delta E_{\mathrm{O}}=0.12 n_{\mathrm{Co}(\mathrm{c})}+0.02 n_{\mathrm{Co}(\mathrm{e})}+0.23\right)$. (c) $\Delta E_{\mathrm{O}}$ values from DFT and the linear regression model (which are labelled as DFT $\Delta E_{\mathrm{O}}$ and Model $\Delta E_{\mathrm{O}}$, respectively), and the numbers of subsurface Co coordinating the $\mathrm{Pt}$ at the corner and edge sites. 

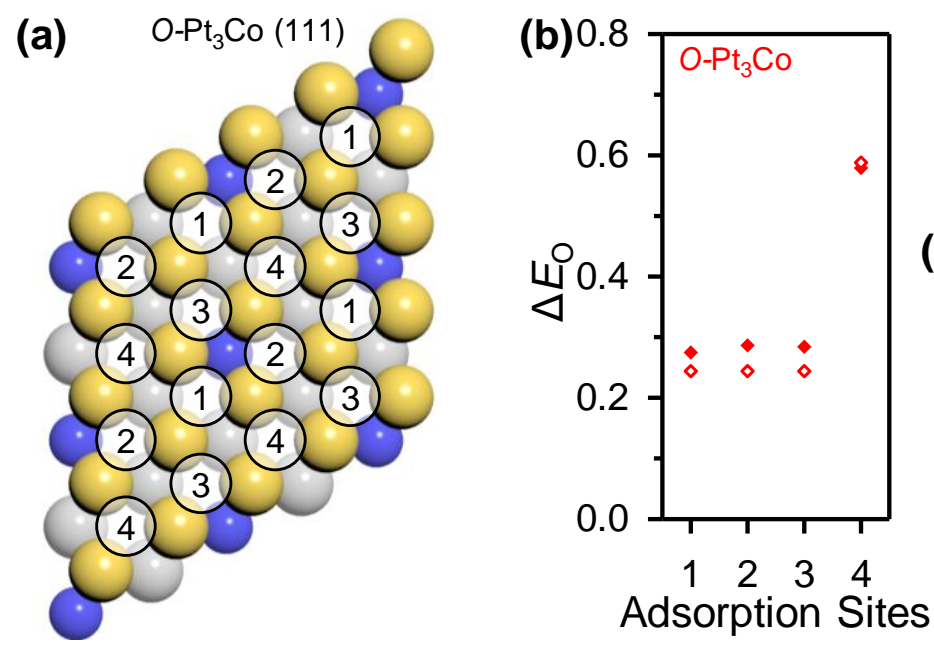

- DFT $\Delta E_{\mathrm{O}}$

- Model $\Delta E_{O}$

Linear Model:

$\Delta E_{\mathrm{O}}=0.12 n_{\mathrm{Co}(\mathrm{c})}+0.02 n_{\mathrm{Co}(\mathrm{e})}+0.23$

(c)

\begin{tabular}{c|cccc}
\hline sites & $\mathbf{1}$ & $\mathbf{2}$ & $\mathbf{3}$ & $\mathbf{4}$ \\
\hline $\begin{array}{c}\mathrm{DFT} \Delta E_{\mathrm{O}} \\
(\mathrm{eV})\end{array}$ & 0.28 & 0.28 & 0.28 & 0.58 \\
$\begin{array}{c}\text { Model } \Delta E_{\mathrm{O}} \\
(\mathrm{eV})\end{array}$ & 0.24 & 0.24 & 0.24 & 0.59 \\
$\begin{array}{c}\text { Coordination } \\
\left(\boldsymbol{n}_{\mathrm{Co}(\mathrm{c})}, \boldsymbol{n}_{\mathrm{Co}(\mathrm{e})}\right)\end{array}$ & $(0,1)$ & $(0,1)$ & $(0,1)$ & $(3,0)$ \\
\hline
\end{tabular}

Figure S3. All possible oxygen adsorption sites of the $O$-Pt ${ }_{3} \mathrm{Co}$ surfaces. (a) All possible oxygen adsorption sites of the $O-\mathrm{Pt}_{3} \mathrm{Co}$ surface are indicated by circles. (b) Comparison between $\Delta E_{\mathrm{O}}$ values from DFT and those from the linear regression model $\left(\Delta E_{\mathrm{O}}=0.12 n_{\mathrm{Co}(\mathrm{c})}+0.02 n_{\mathrm{Co}(\mathrm{e})}+0.23\right)$. (c) $\Delta E_{\mathrm{O}}$ values from DFT and the linear regression model (which are labelled as DFT $\Delta E_{\mathrm{O}}$ and Model $\Delta E_{\mathrm{O}}$, respectively), and the numbers of subsurface Co coordinating the $\mathrm{Pt}$ at the corner and edge sites. 


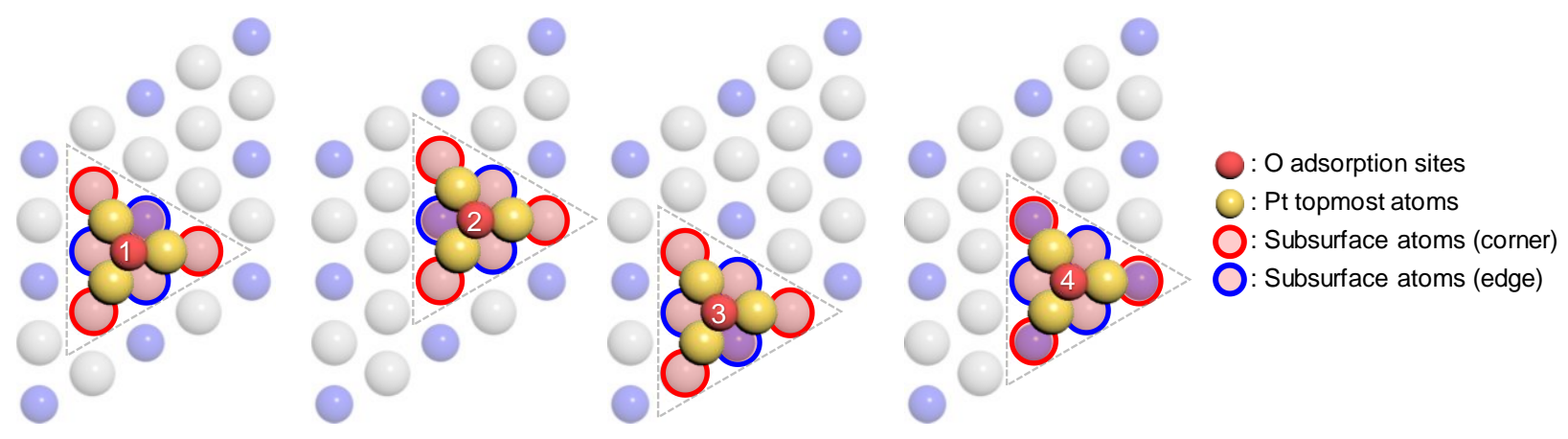

Figure S4. Four possible active sites of $O$ - $\mathrm{Pt}_{3} \mathrm{Co}$ surfaces, having different Co subsurface coordinating environments. Three of the four possible active sites are symmetrically identical (labelled as 1,2 , and 3 , where $n_{\mathrm{Co}(\mathrm{c})}=0$ and $n_{\mathrm{Co}(\mathrm{e})}=1$ ), while one is unlike (labelled as 4 , where $n_{\mathrm{Co}(\mathrm{c})}=3$ and $\left.n_{\mathrm{Co}(\mathrm{e})}=0\right)$. 
(a)

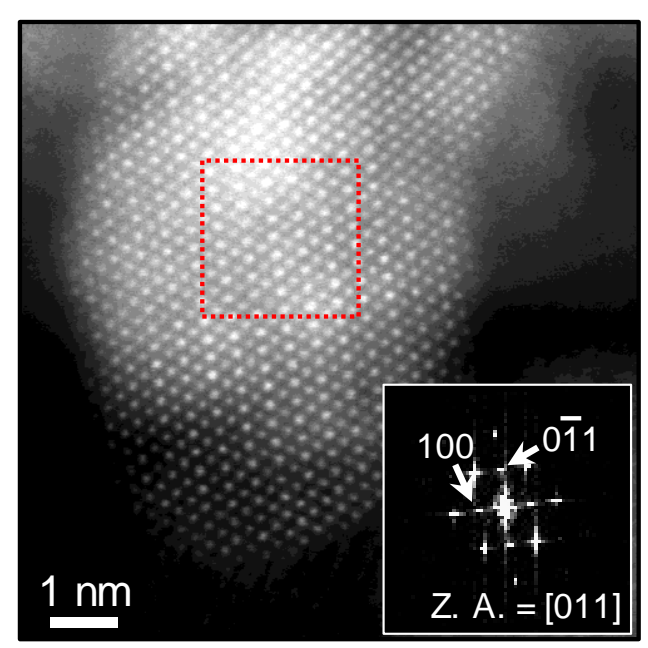

(b)

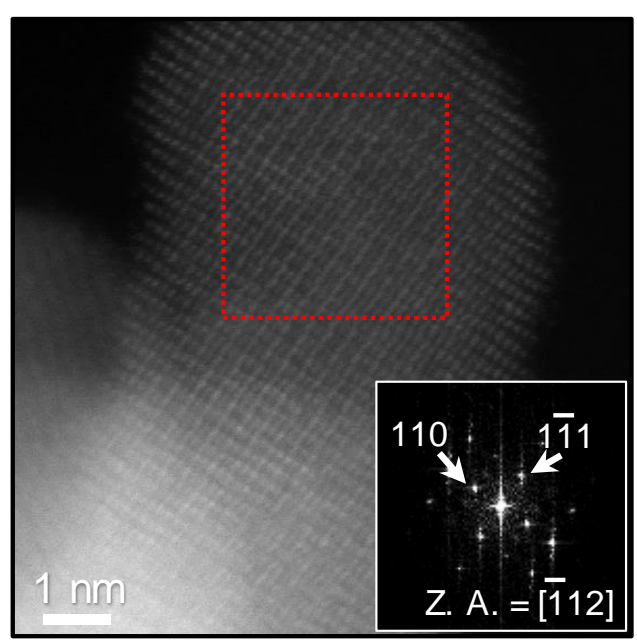

(c)

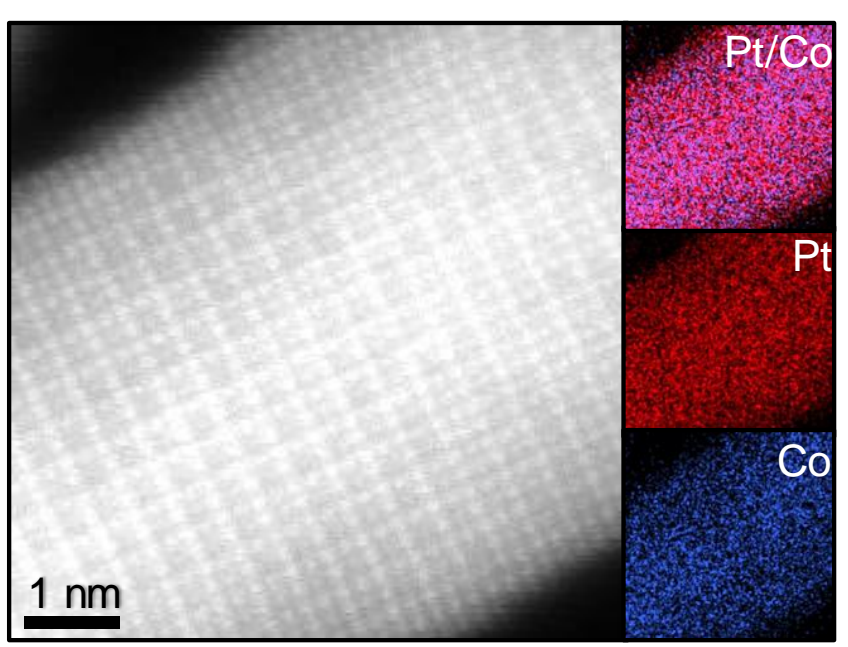

Figure S5. Additional HAADF-STEM images and EDS elemental maps of $O-\mathrm{Pt}_{3} \mathrm{Co}$ NWs. (a, b) HAADF-STEM images of $O-\mathrm{Pt}_{3} \mathrm{Co}$ NWs. The insets show the FFT patterns of the dotted red square areas. (c) HAADF-STEM image and the corresponding EDS elemental maps for Pt and Co, $\mathrm{Pt}$, and Co. 
(a)

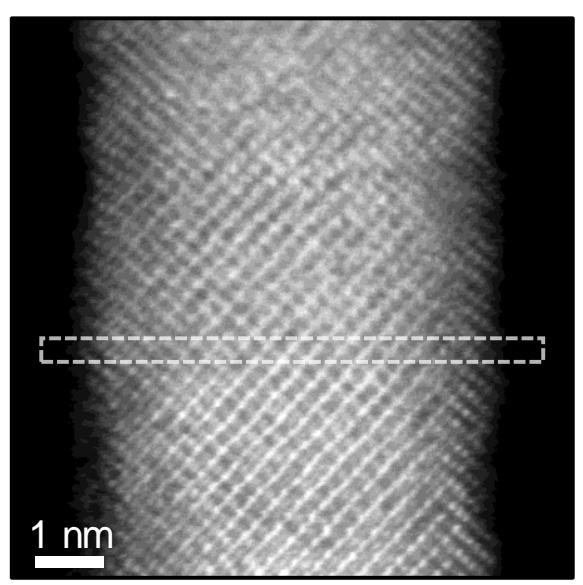

(b)

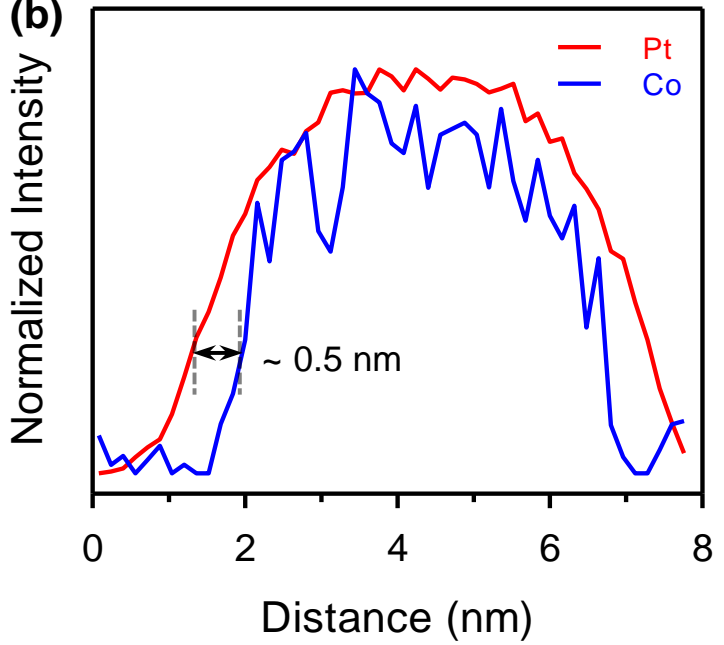

Figure S6. EELS line profile analysis of $O-\mathrm{Pt}_{3} \mathrm{Co} \mathrm{NWs}$. (a) HAADF-STEM image of $O$ - $\mathrm{Pt}_{3} \mathrm{Co}$ NWs. (b) EELS line profiles extracted from the dashed white area in (a) showing that the thickness of Pt shell is $\sim 0.5 \mathrm{~nm}$. 

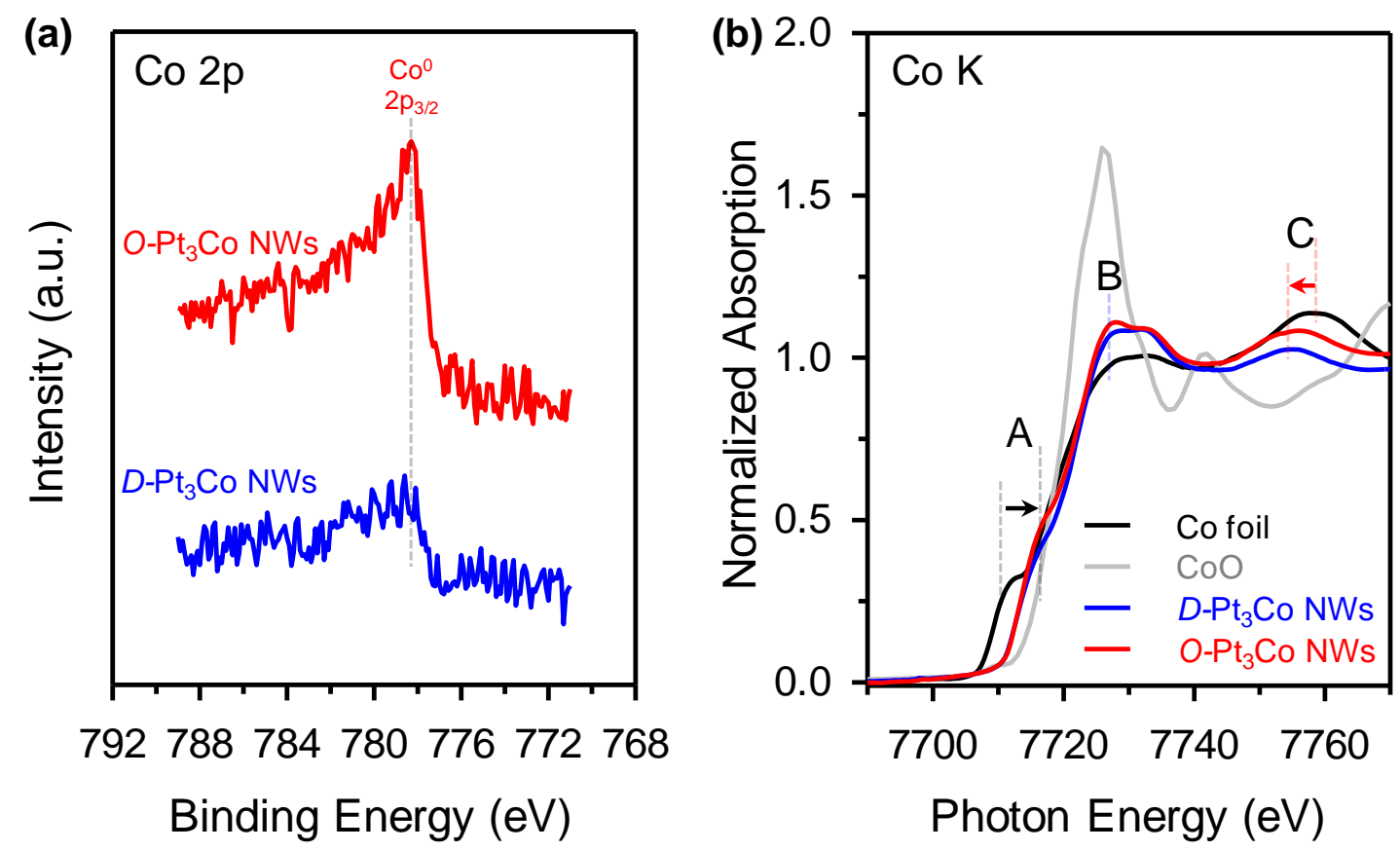

Figure S7. Co $2 \mathrm{p}$ XPS and Co K-edge XANES spectra of $D-\mathrm{Pt}_{3} \mathrm{Co} \mathrm{NWs}$ and $O$-Pt ${ }_{3} \mathrm{Co}$ NWs. (a) Co 2 p XPS spectra of $D$-Pt ${ }_{3}$ Co NWs and $O$-Pt ${ }_{3}$ Co NWs. (b) Co K-edge XANES spectra of $D$ $\mathrm{Pt}_{3} \mathrm{Co} \mathrm{NWs}$ and $O-\mathrm{Pt}_{3} \mathrm{Co} \mathrm{NWs}$, along with those of $\mathrm{Co}$ foil and $\mathrm{CoO}$ references. 

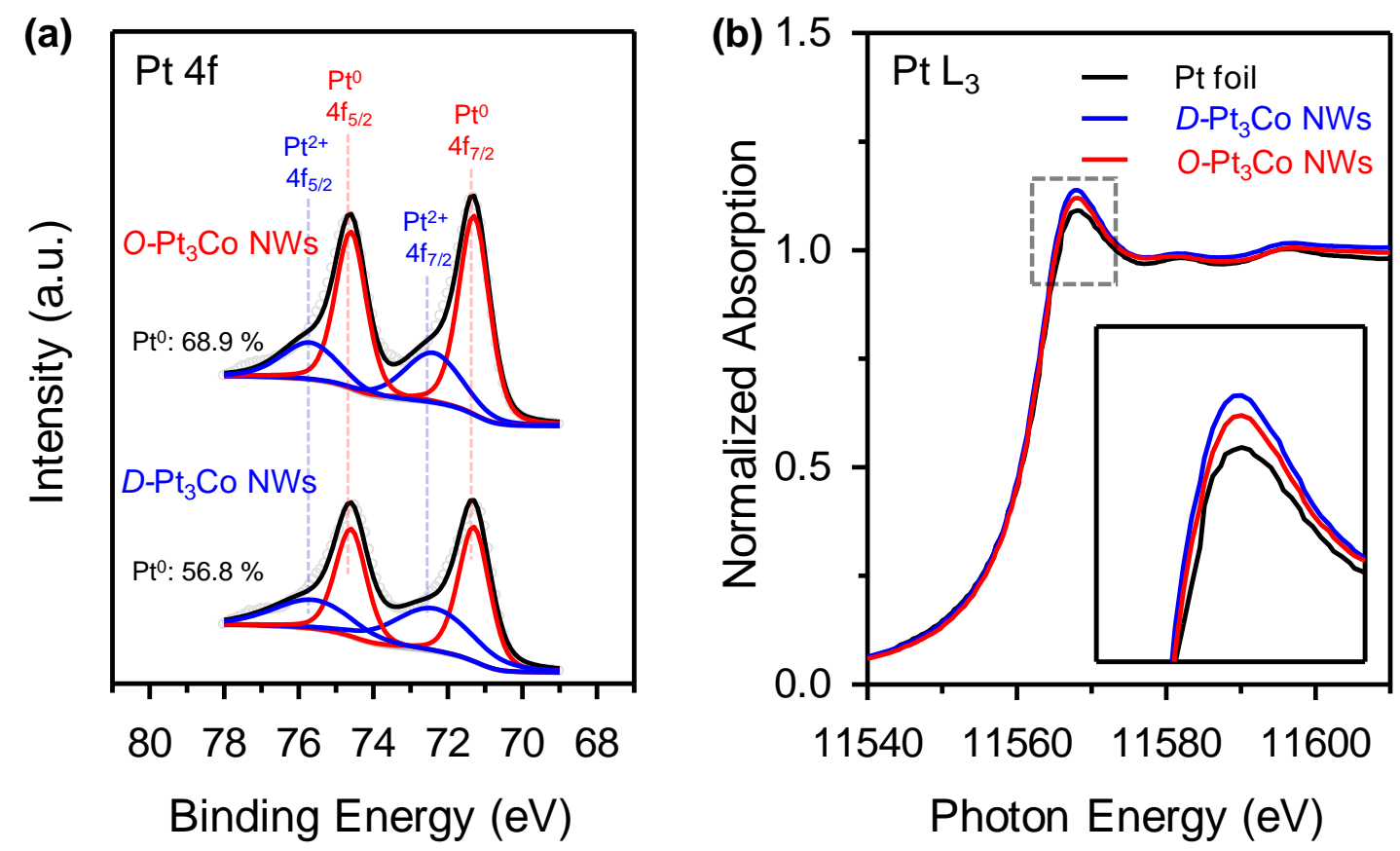

Figure S8. Pt $4 \mathrm{f}$ XPS and $\mathrm{Pt} \mathrm{L}_{3}$-edge XANES spectra of $D-\mathrm{Pt}_{3} \mathrm{Co} \mathrm{NWs}$ and $O$-Pt $\mathrm{Pt}_{3} \mathrm{Co} \mathrm{NWs}$. (a) Pt 4f XPS spectra of $D-\mathrm{Pt}_{3} \mathrm{Co} \mathrm{NWs}$ and $O-\mathrm{Pt}_{3} \mathrm{Co} \mathrm{NWs}$. The ratios of $\mathrm{Pt}^{0}$ metallic species of the catalysts are given in the plot. (b) $\mathrm{Pt} \mathrm{L}_{3}$-edge XANES spectra of $D$ - $\mathrm{Pt}_{3} \mathrm{Co} \mathrm{NWs}$ and $O$ - $\mathrm{Pt}_{3} \mathrm{Co} \mathrm{NWs}_{\text {, }}$ along with Pt foil reference. The inset shows a magnified view of the region within the grey dashed box in the XANES spectra. 


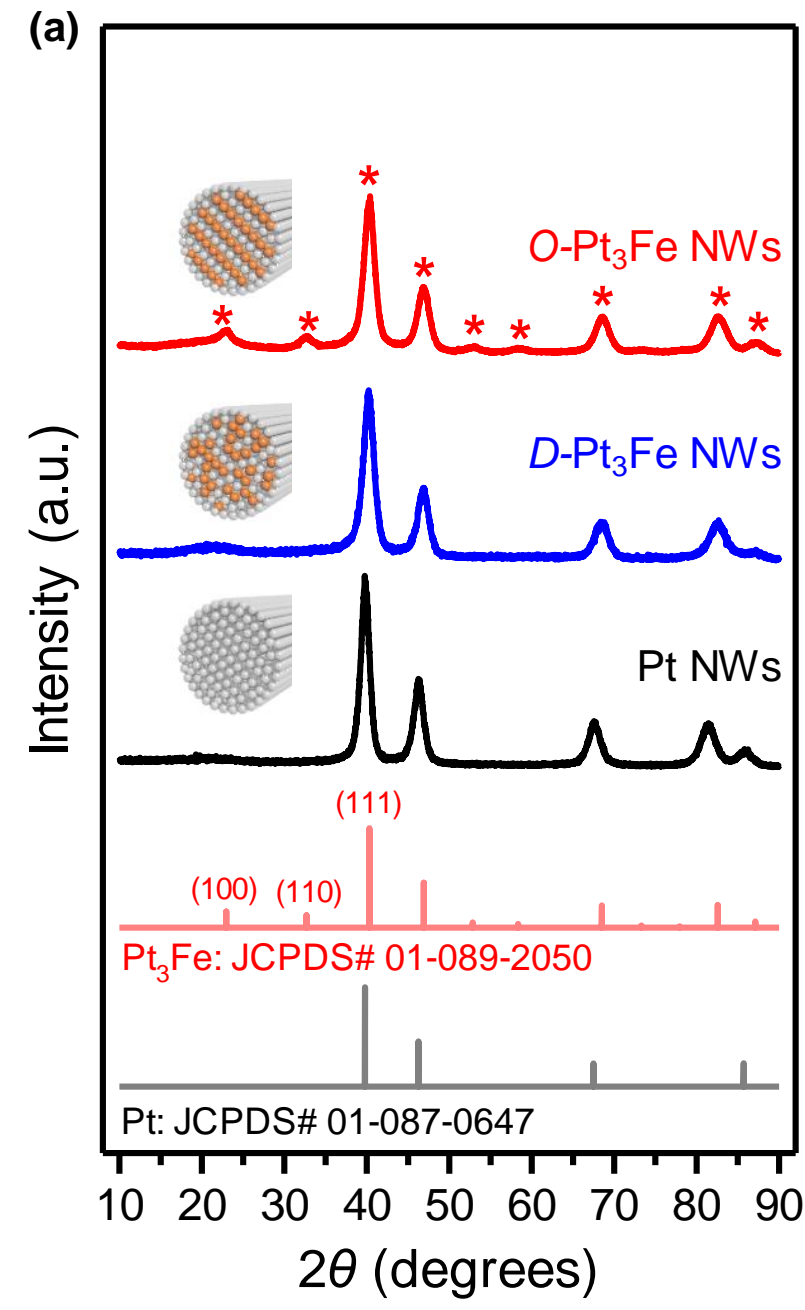

(b)

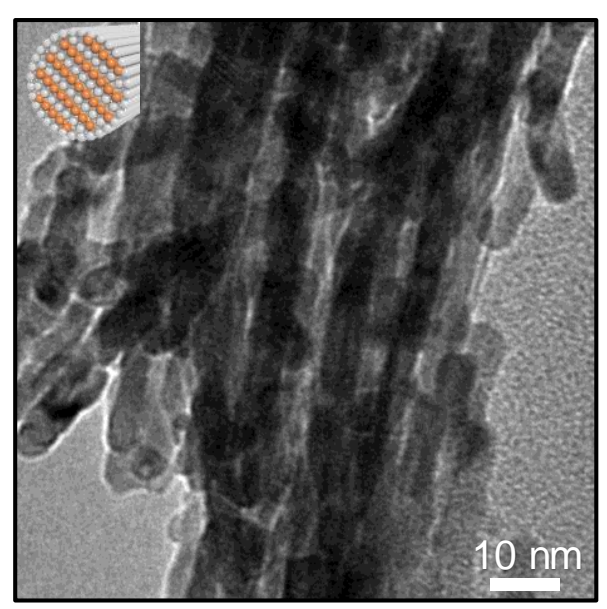

(c)

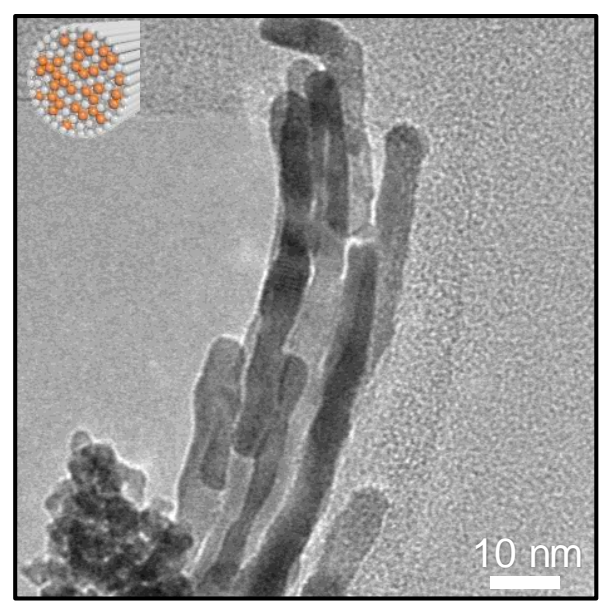

Figure S9. XRD patterns and TEM images of $\mathrm{Pt}_{3} \mathrm{Fe}$ NWs. (a) XRD patterns of $O-\mathrm{Pt}_{3} \mathrm{Fe}$ NWs, $D$ $\mathrm{Pt}_{3} \mathrm{Fe}$ NWs, and Pt NWs. The grey and pink vertical lines indicate the peak positions of the Pt (JCPDS \# 01-087-0647) and intermetallic Pt ${ }_{3} F e$ reflections (JCPDS \# 01-089-2050). (b, c) TEM images of (b) $O-\mathrm{Pt}_{3} \mathrm{Fe}$ NWs and (c) $D-\mathrm{Pt}_{3} \mathrm{Fe} \mathrm{NWs}$, respectively. Insets in (b, c) show models for ordered intermetallic and random alloy structures. 


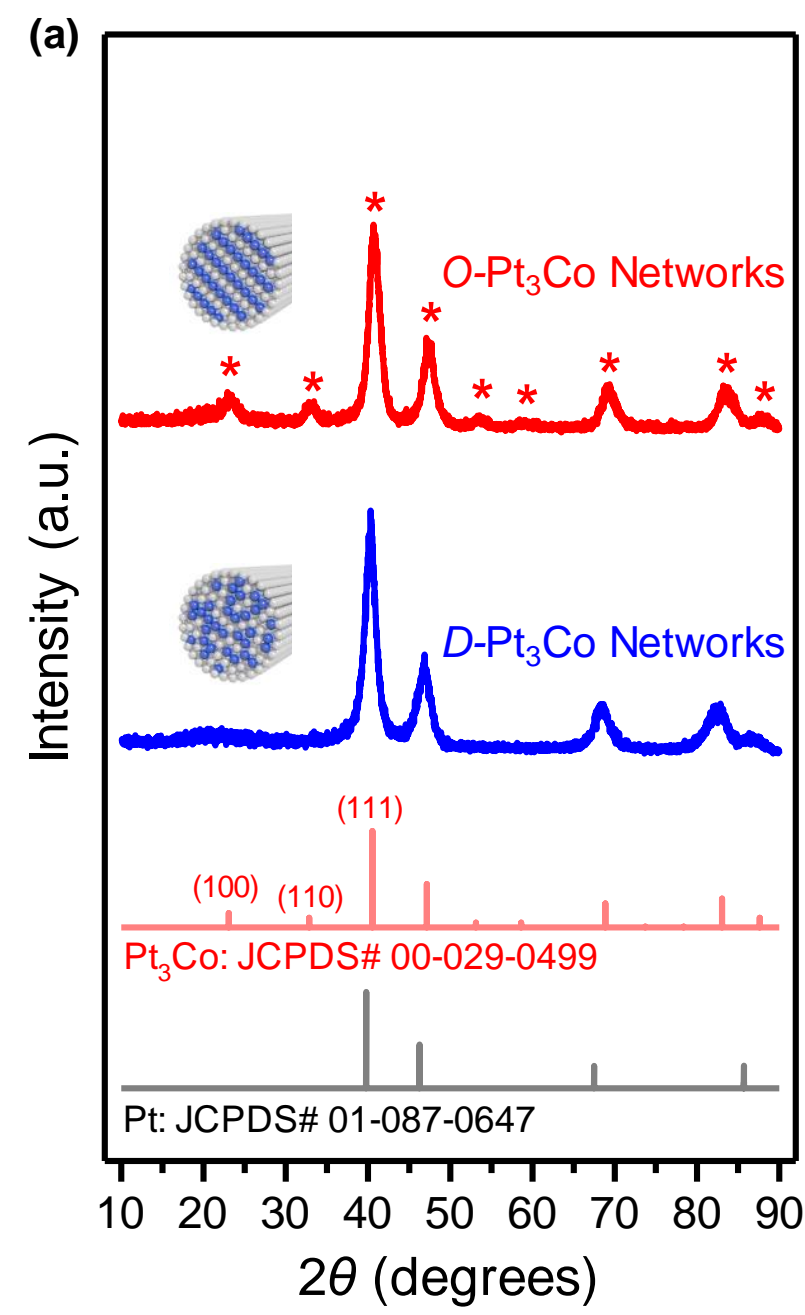

(b)

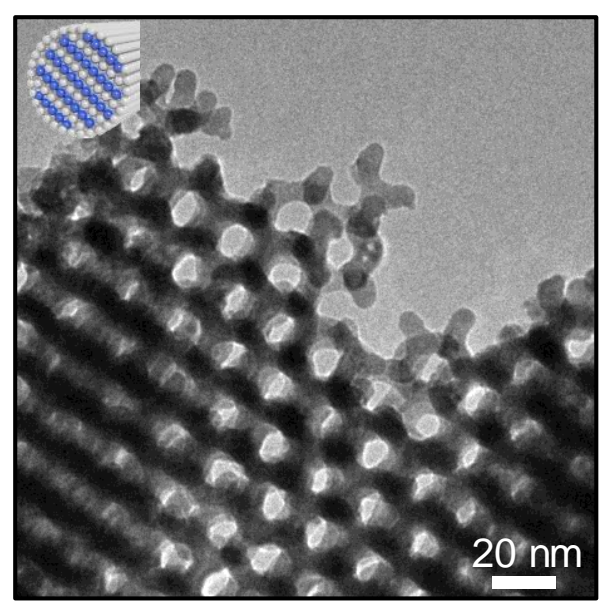

(c)

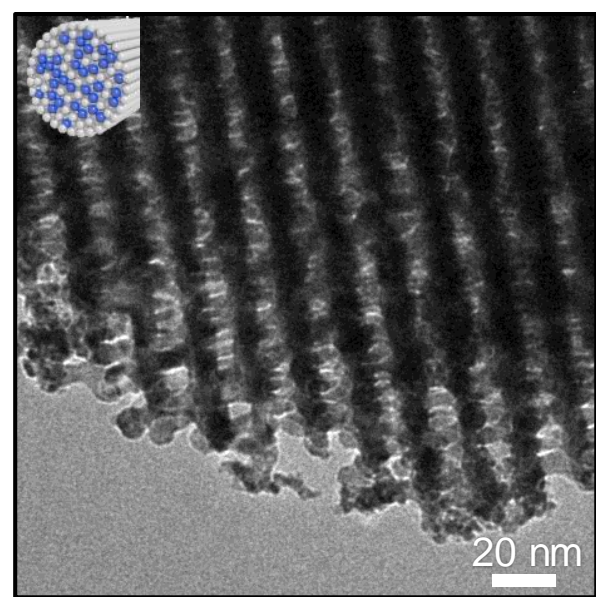

Figure S10. XRD patterns and TEM images of $\mathrm{Pt}_{3} \mathrm{Co}$ Networks. (a) XRD patterns of $O$-Pt $\mathrm{Co}_{3}$ Networks and $D$ - $\mathrm{Pt}_{3} \mathrm{Co}$ Networks. The grey and pink vertical lines indicate the peak positions of the Pt (JCPDS \# 01-087-0647) and intermetallic Pt ${ }_{3}$ Co reflections (JCPDS \# 00-029-0499). (b, c) TEM images of (b) $O-\mathrm{Pt}_{3} \mathrm{Co}$ Networks and (c) $D$-Pt ${ }_{3} \mathrm{Co}$ Networks, respectively. Insets in (b, c) show models for ordered intermetallic and random alloy structures. 

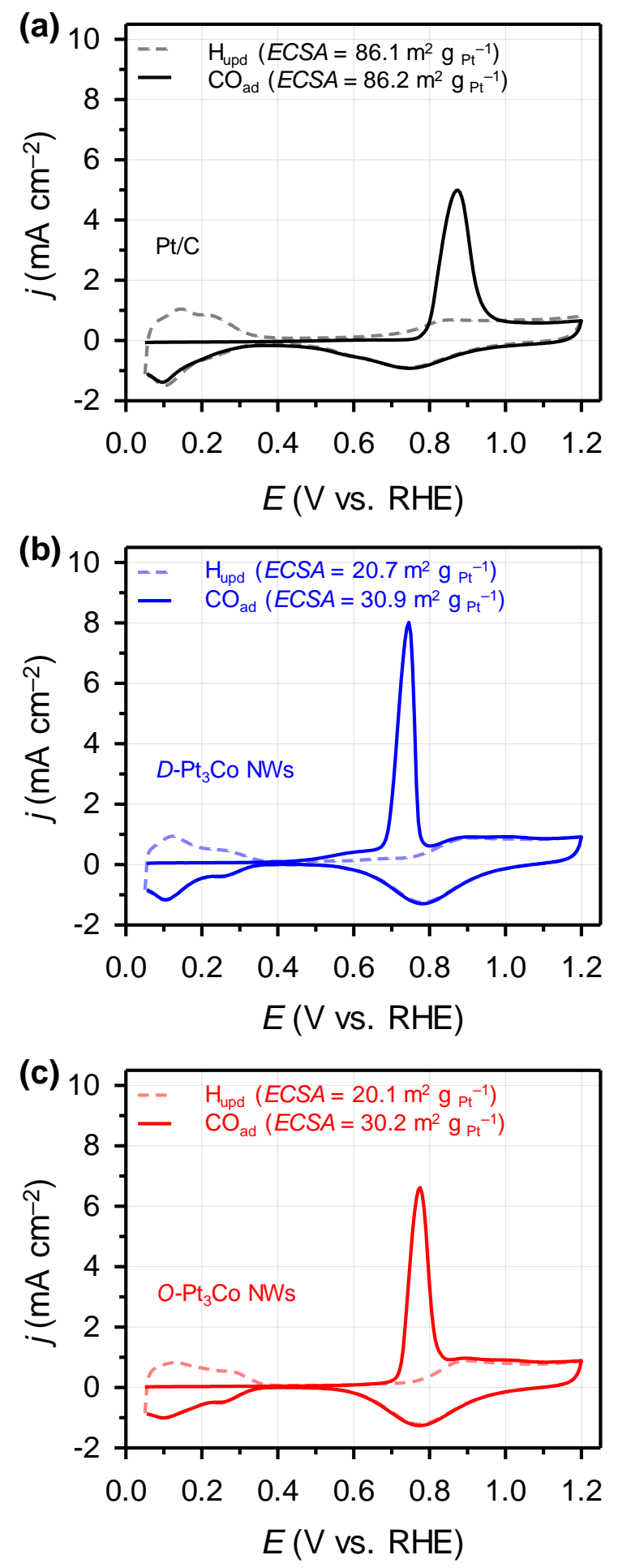

Figure S11. ECSAs of the catalysts measured by hydrogen underpotential deposition and $\mathrm{CO}$ stripping. (a) $\mathrm{Pt} / \mathrm{C}$. (b) $D$-Pt ${ }_{3} \mathrm{Co} \mathrm{NWs}$. (c) $O-\mathrm{Pt}_{3} \mathrm{Co} \mathrm{NWs}$. The calculated ECSA values are given in parentheses in the legends. 


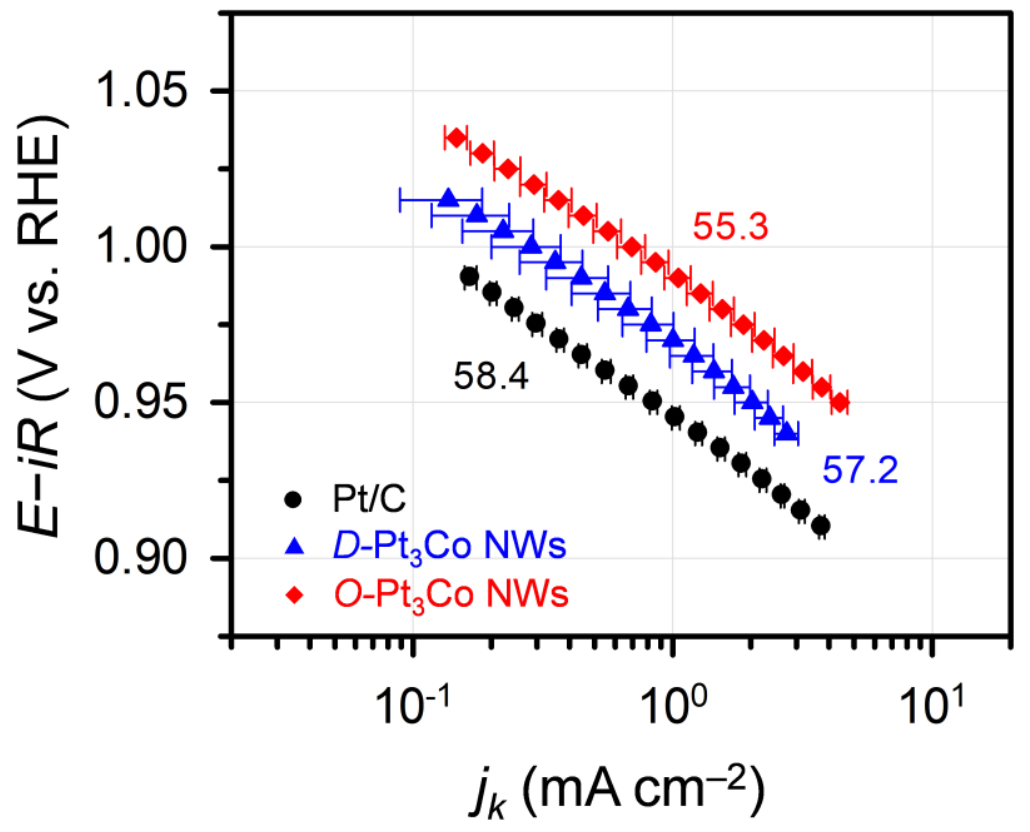

Figure S12. ORR Tafel plots of the catalysts. Tafel slopes of the catalysts are given in the plot. 


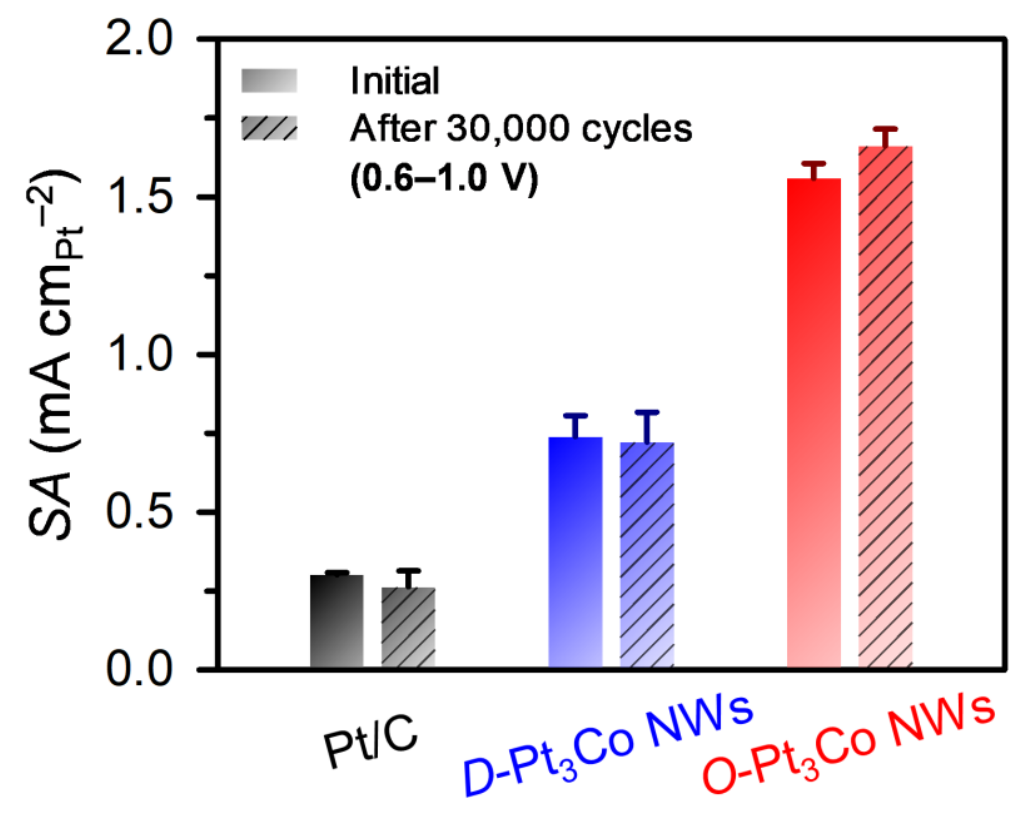

Figure S13. ORR specific activities of the catalysts before and after the ORR catalyst ADT. 

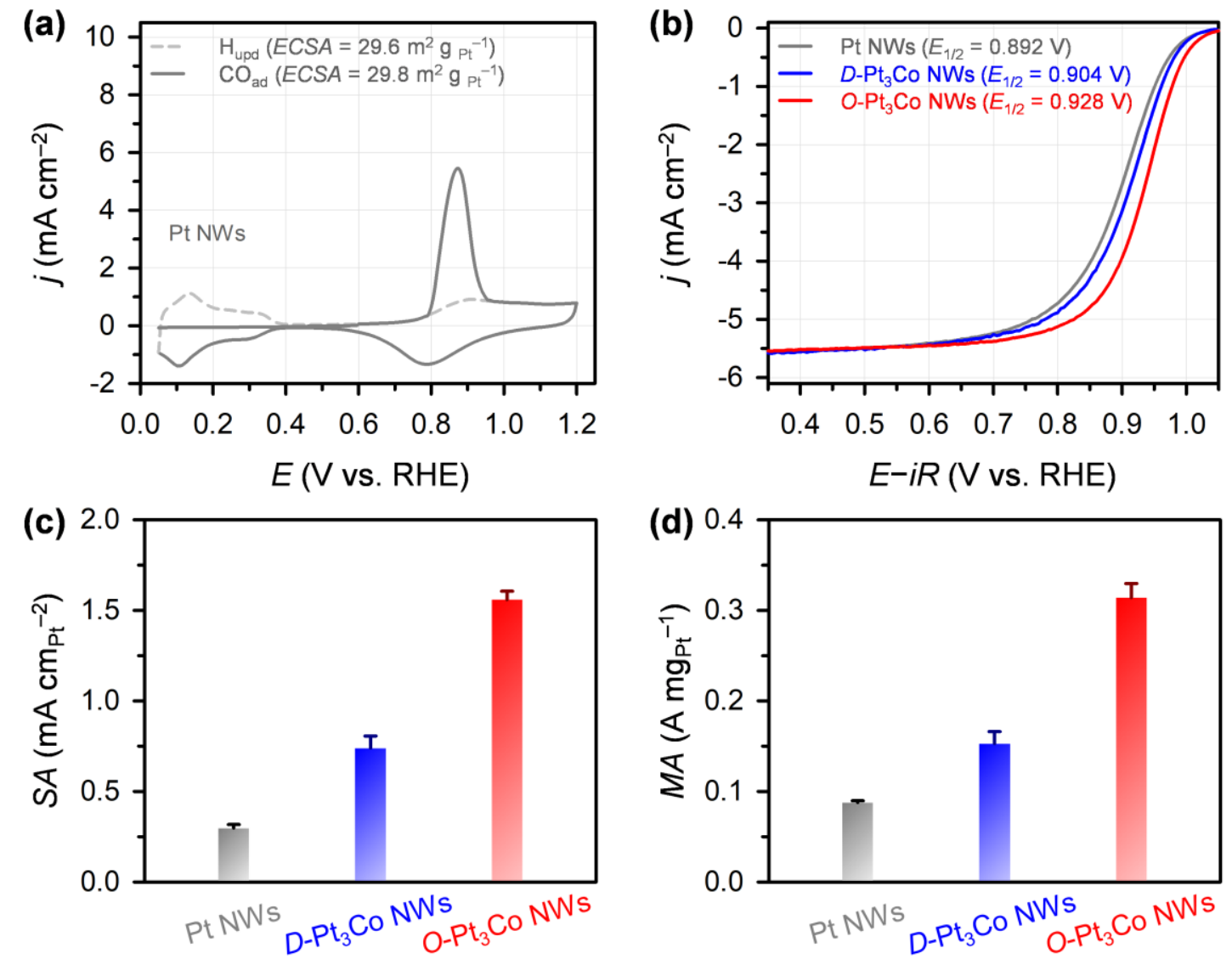

Figure S14. Electrocatalytic activities of Pt NWs. (a) ECSA of Pt NWs catalyst measured by the $\mathrm{H}_{\text {upd }}$ and $\mathrm{CO}_{\text {ad }}$ methods. The estimated ECSA values are given in parentheses in the legend. (b) ORR polarization curves of $\mathrm{Pt} N W s, D-\mathrm{Pt}_{3} \mathrm{Co} \mathrm{NWs}$, and $O$ - $\mathrm{Pt}_{3} \mathrm{Co}$ NWs. (c) ORR specific activities and (d) mass activities of Pt NWs, $D-\mathrm{Pt}_{3} \mathrm{Co} \mathrm{NWs}$, and $O$ - $\mathrm{Pt}_{3} \mathrm{Co} \mathrm{NWs}$. 

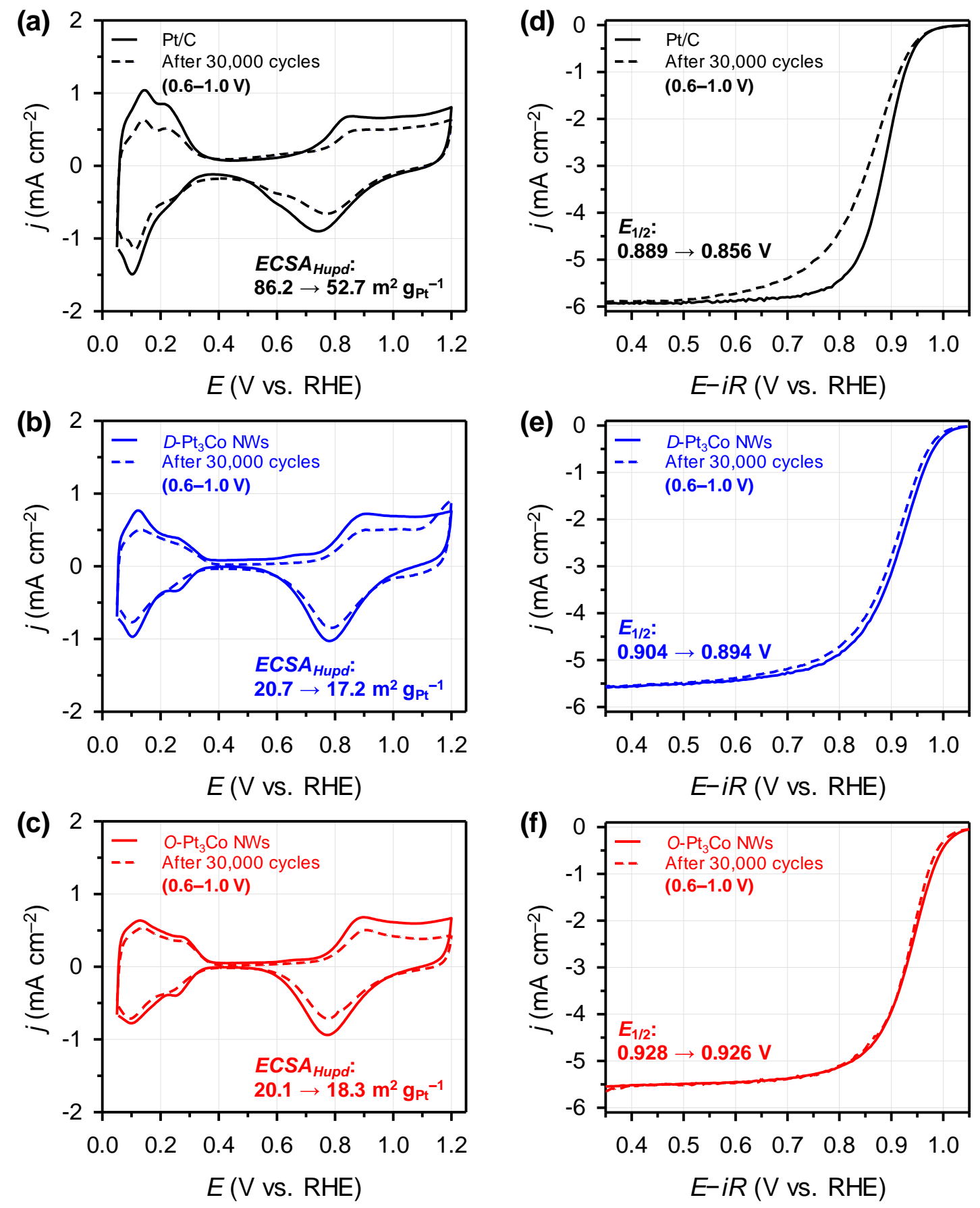

Figure S15. Electrocatalytic properties of the catalysts before and after the ORR catalyst ADT. (a-c) CVs and (d-f) ORR polarization curves of (a, d) Pt/C, (b, e) $D$-Pt ${ }_{3} \mathrm{Co} N W s$, and (c, f) $O$ $\mathrm{Pt}_{3} \mathrm{Co} \mathrm{NWs}$ before and after 30,000 cycles of ORR catalyst ADT in the range of 0.6-1.0 V. 


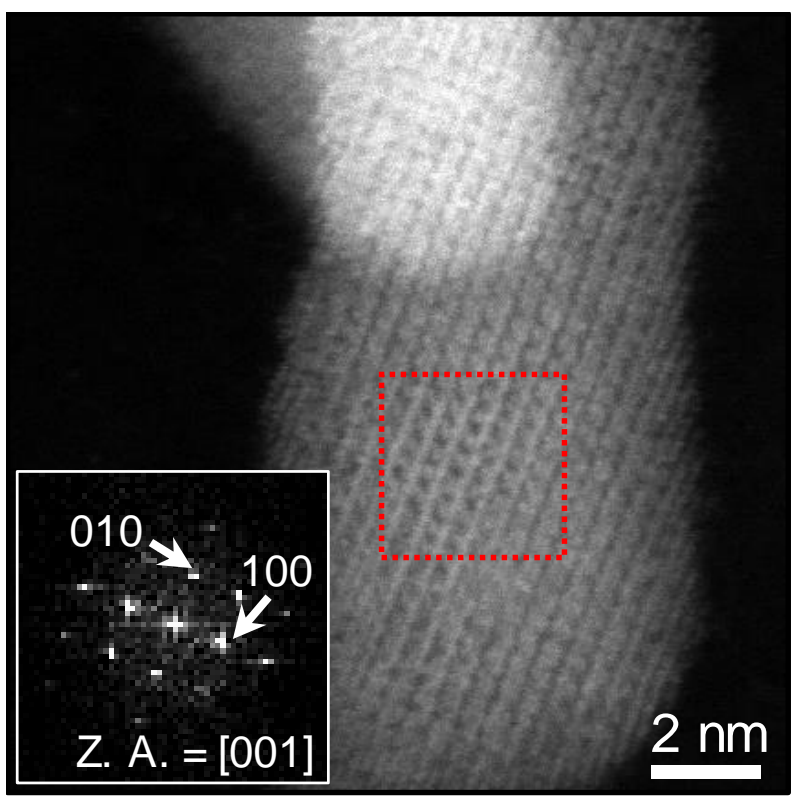

Figure S16. Additional HAADF-STEM image of $O-\mathrm{Pt}_{3} \mathrm{Co} \mathrm{NWs}$ after 30,000 cycles of ORR catalyst ADT. 

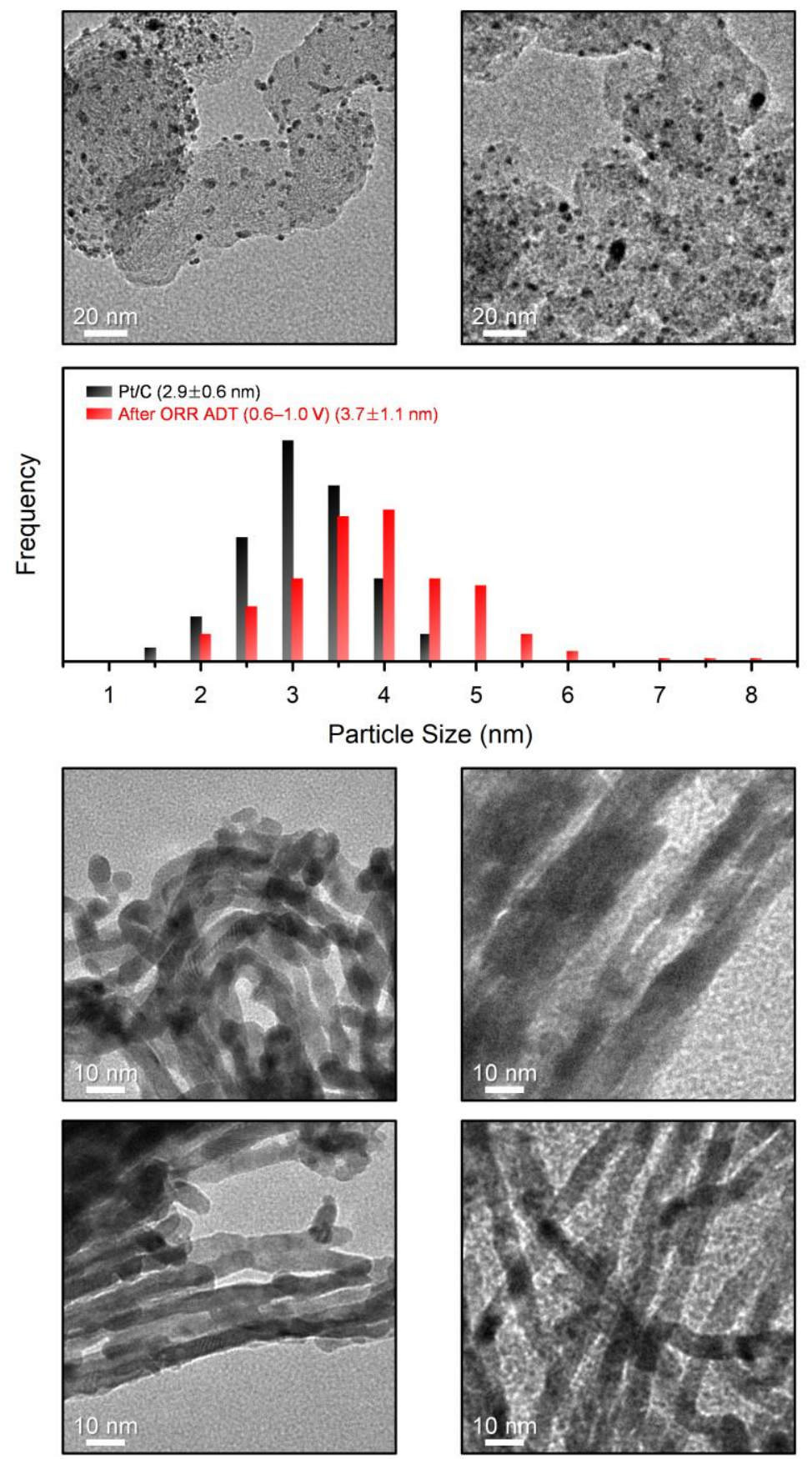

Figure S17. TEM analyses of the catalysts before and after the ORR catalyst ADT. (a, b) TEM images of Pt/C catalyst (a) before and (b) after 30,000 cycles of ORR catalyst ADT in the range of 0.6-1.0 V. (c) Particle size distribution histograms of Pt nanoparticles in Pt/C before and after the ORR catalyst ADT. (d, e) TEM images of $D$-Pt ${ }_{3} C o$ NWs catalyst (d) before and (e) after 30,000 cycles of ORR catalyst ADT. (f, g) TEM images of $O-\mathrm{Pt}_{3} \mathrm{Co}$ NWs catalyst (f) before and (g) after 30,000 cycles of ORR catalyst ADT. 

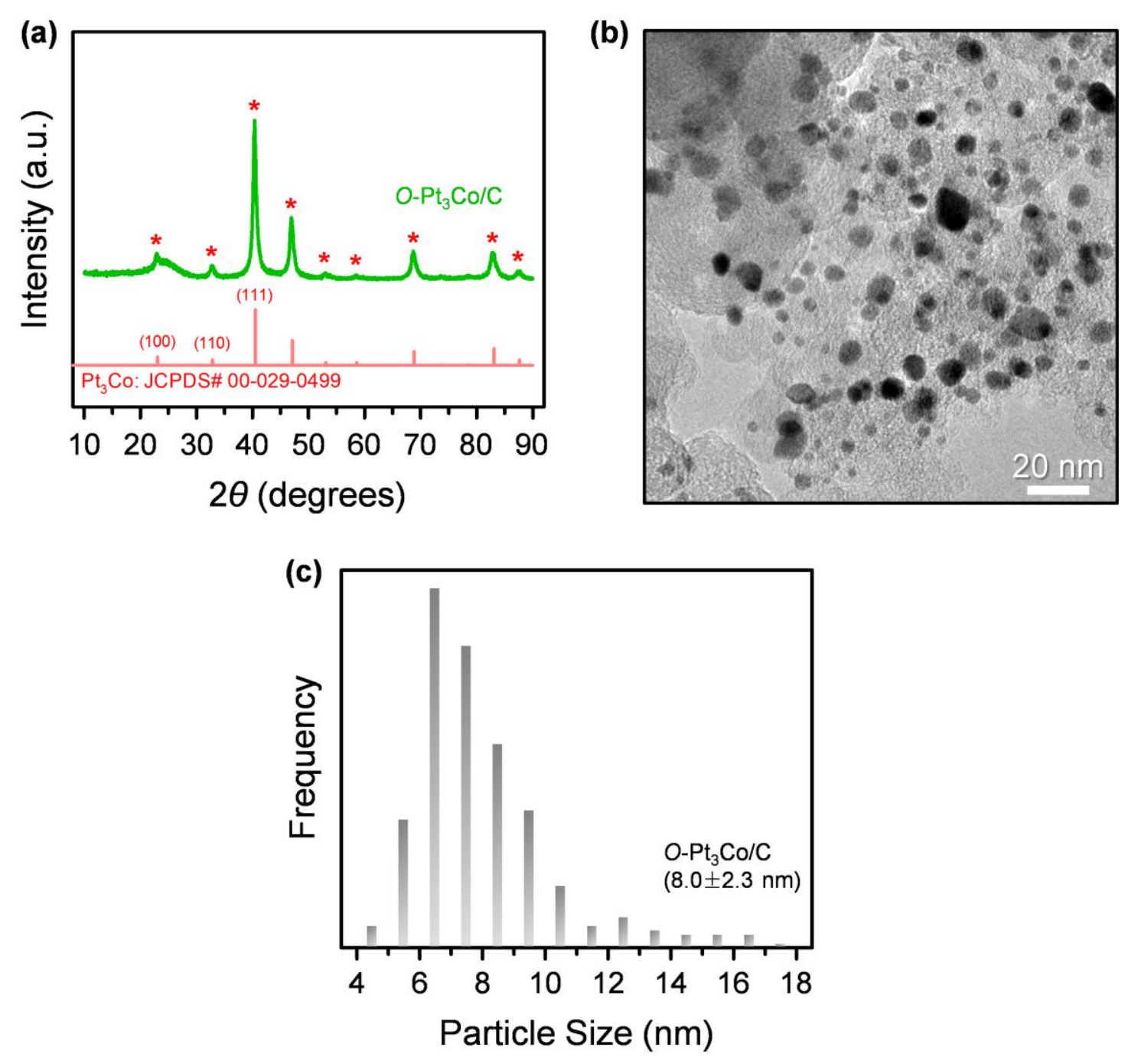

Figure S18. Structural analyses of $O-\mathrm{Pt}_{3} \mathrm{Co} / \mathrm{C}$ catalyst. (a) XRD pattern of ordered intermetallic $O-\mathrm{Pt}_{3} \mathrm{Co} / \mathrm{C}$ catalyst. The pink vertical lines indicate the peak positions of the intermetallic $\mathrm{Pt}_{3} \mathrm{Co}$ reflections (JCPDS \# 00-029-0499). (b) TEM image of $O-\mathrm{Pt}_{3} \mathrm{Co} / \mathrm{C}$ catalyst. (c) Particle size distribution histogram of $O-\mathrm{Pt}_{3} \mathrm{Co}$ nanoparticles obtained from TEM images. The average particle size is given in the plot. 

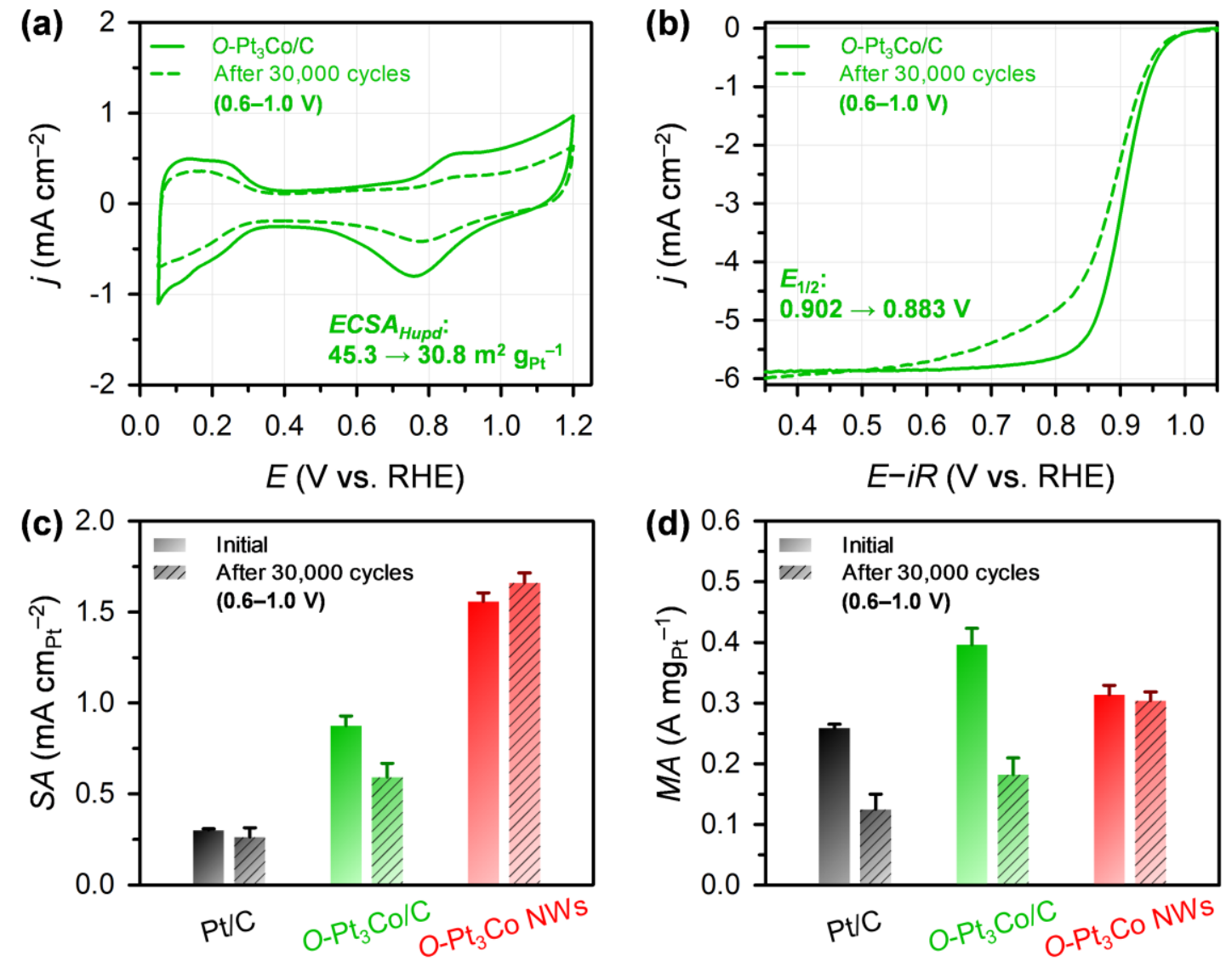

Figure S19. Electrocatalytic properties of $O-\mathrm{Pt}_{3} \mathrm{Co} / \mathrm{C}$ before and after the ORR Catalyst ADT. (a) $\mathrm{CVs}$ and (b) ORR polarization curves of $O-\mathrm{Pt}_{3} \mathrm{Co} / \mathrm{C}$ catalyst before and after 30,000 cycles of ORR catalyst ADT in the range of 0.6-1.0 V. (c) ORR specific activities and (d) mass activities of Pt/C, $O-\mathrm{Pt}_{3} \mathrm{Co} / \mathrm{C}$, and $O-\mathrm{Pt}_{3} \mathrm{Co}$ NWs before and after 30,000 cycles of ORR catalyst ADT. 

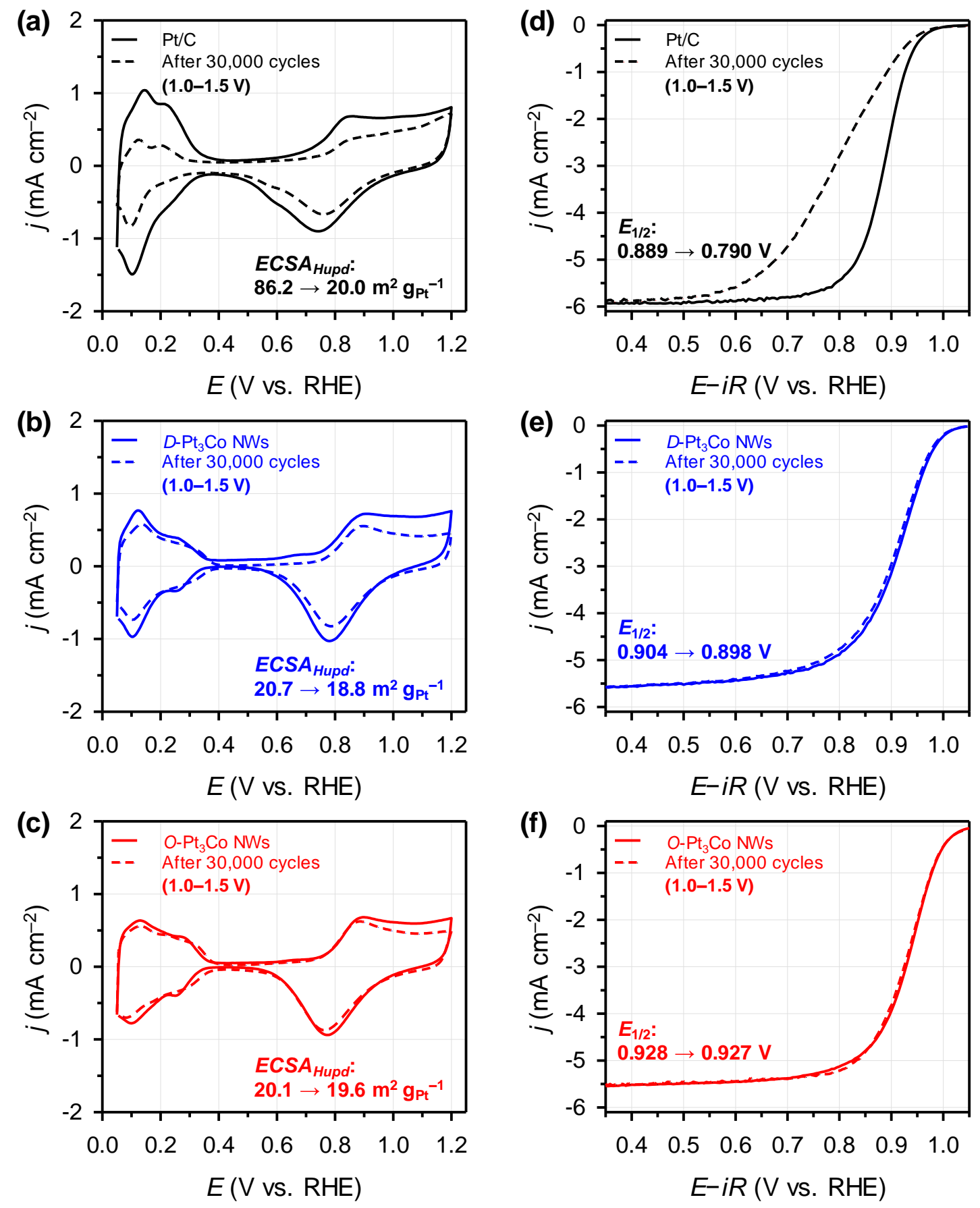

Figure S20. Electrocatalytic properties of the catalysts before and after the ORR support ADT. (a-c) CVs and (d-f) ORR polarization curves of (a, d) Pt/C, (b, e) $D$-Pt ${ }_{3} \mathrm{Co} N W s$, and (c, f) $O$ $\mathrm{Pt}_{3} \mathrm{Co} \mathrm{NWs}$ before and after 30,000 cycles of ORR support ADT in the range of 1.0-1.5 V. 


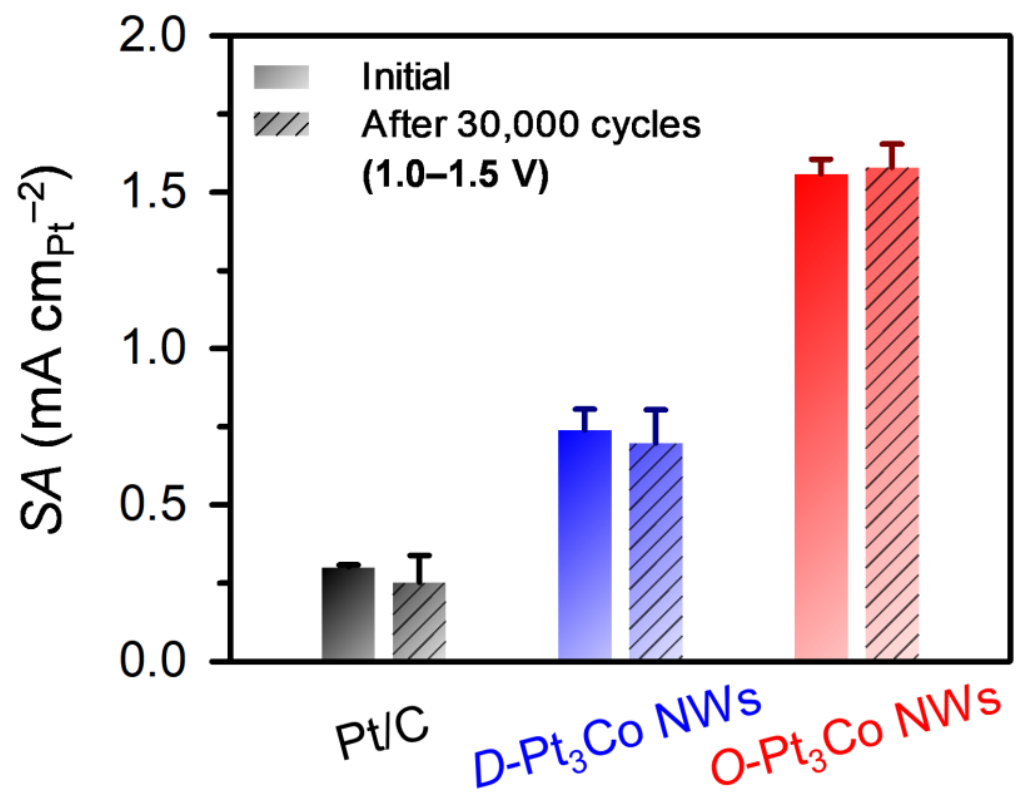

Figure S21. ORR specific activities of the catalysts before and after the ORR support ADT. 

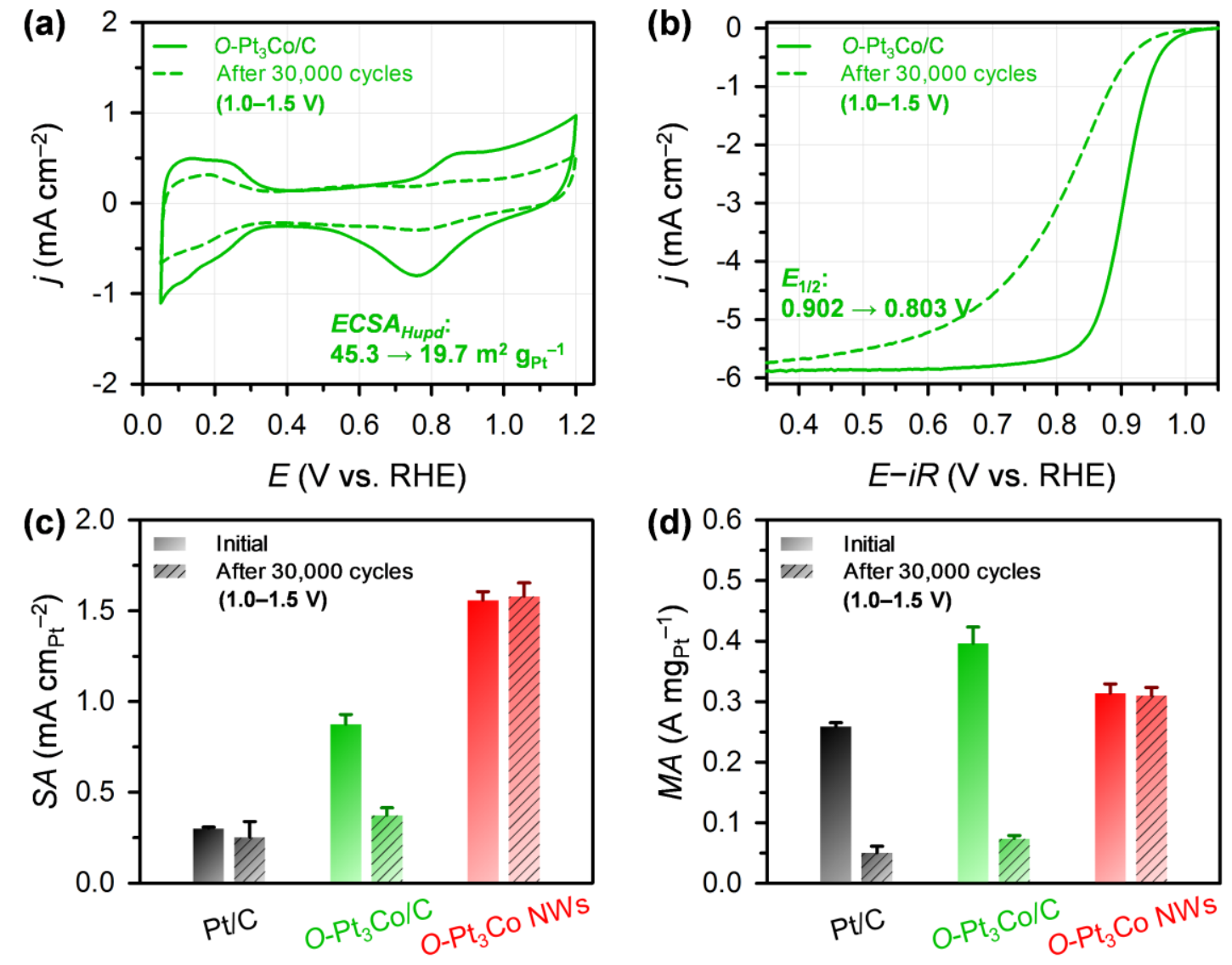

Figure S22. Electrocatalytic properties of $O-\mathrm{Pt}_{3} \mathrm{Co} / \mathrm{C}$ before and after the ORR support ADT. (a) $\mathrm{CVs}$ and (b) ORR polarization curves of $O-\mathrm{Pt}_{3} \mathrm{Co} / \mathrm{C}$ catalyst before and after 30,000 cycles of ORR catalyst ADT in the range of 1.0-1.5 V. (c) ORR specific activities and (d) mass activities of Pt/C, $O-\mathrm{Pt}_{3} \mathrm{Co} / \mathrm{C}$, and $O-\mathrm{Pt}_{3} \mathrm{Co}$ NWs before and after 30,000 cycles of ORR catalyst ADT. 
(a)

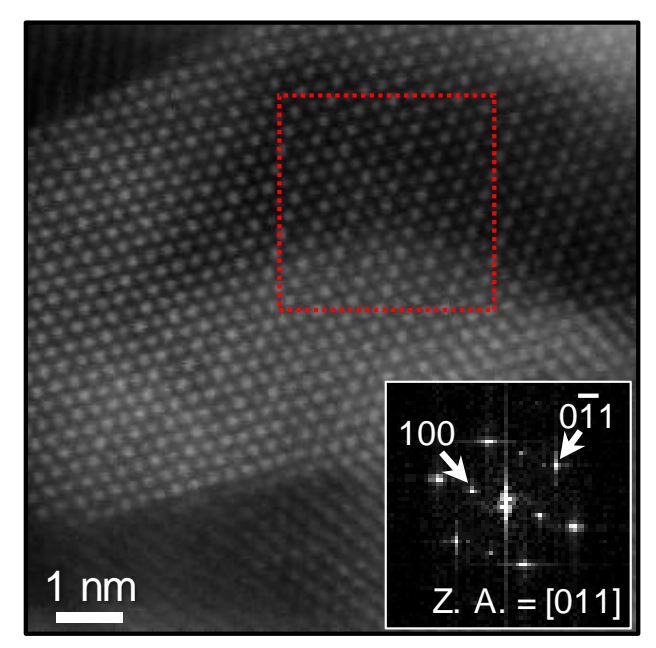

(b)

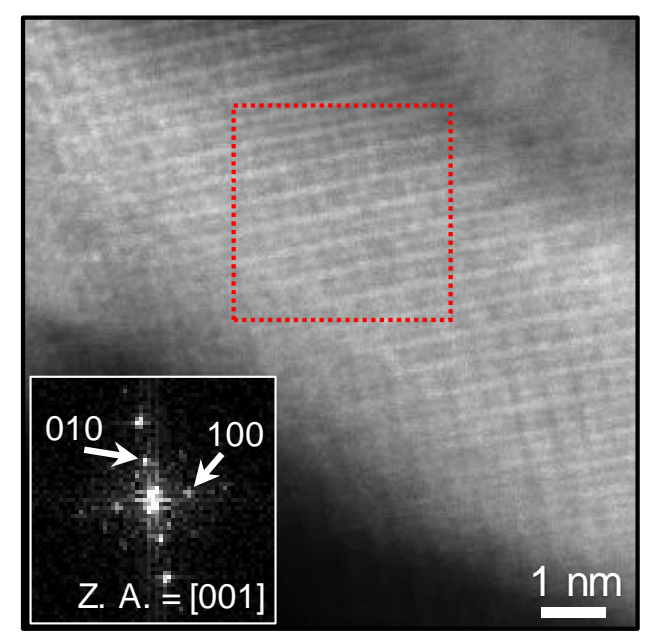

(c)

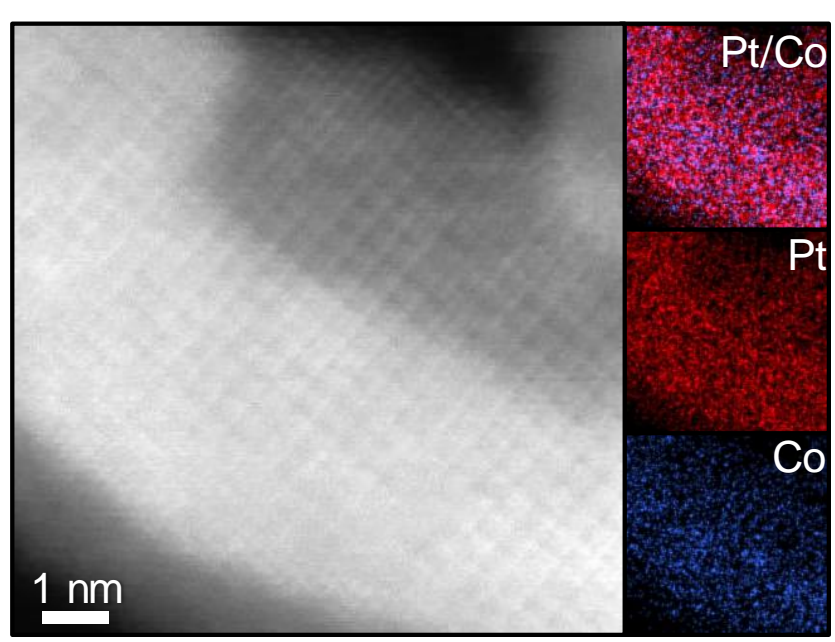

Figure S23. HAADF-STEM and EDS elemental maps of $O$-Pt $\mathrm{t}_{3} \mathrm{Co} \mathrm{NWs}$ after the ORR support ADT. (a, b) HAADF-STEM images of $O-\mathrm{Pt}_{3} \mathrm{Co}$ NWs. The insets show the FFT patterns of the red dotted square areas. (c) HAADF-STEM image and the corresponding EDS elemental maps of Pt and $\mathrm{Co}, \mathrm{Pt}$, and $\mathrm{Co}$. 


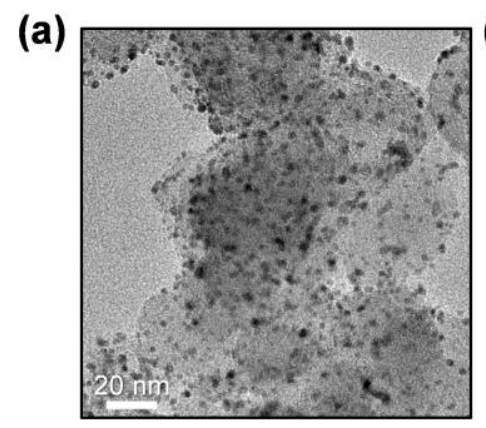

(b)

(c)
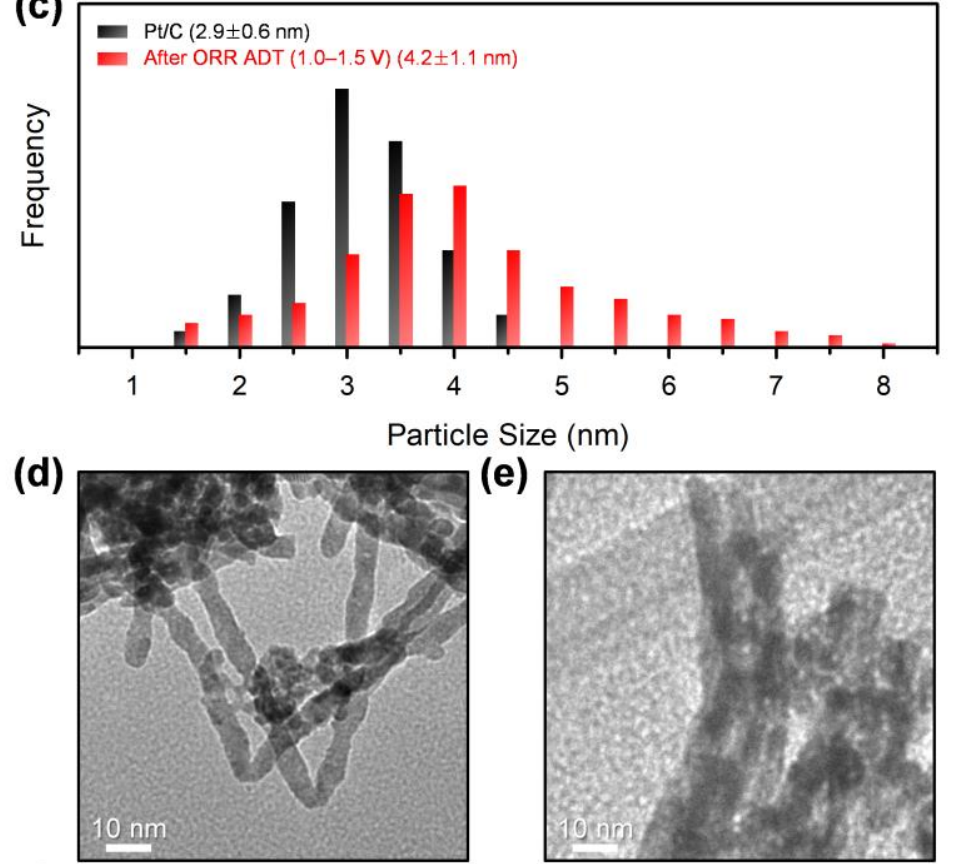

(e)

(f)
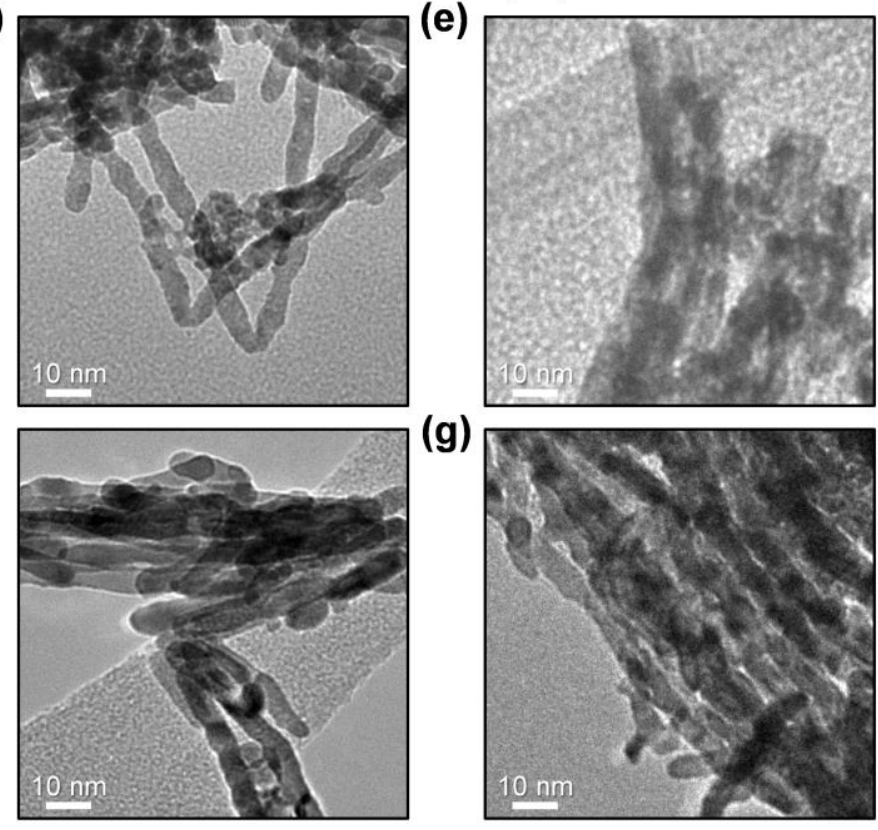

(g)

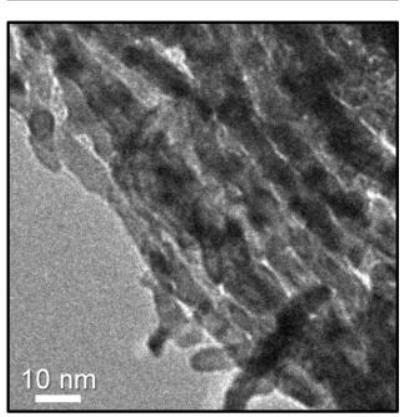

Figure S24. TEM analyses of the catalysts before and after the ORR support ADT. (a, b) TEM images of Pt/C catalyst (a) before and (b) after 30,000 cycles of ORR support ADT in the range of 1.0-1.5 V. (c) Particle size distribution histograms of Pt nanoparticles in Pt/C before and after the ORR support ADT. (d, e) TEM images of $D$-Pt ${ }_{3}$ Co NWs catalyst (d) before and (e) after 30,000 cycles of ORR support ADT. (f, g) TEM images of $O-\mathrm{Pt}_{3} \mathrm{Co}$ NWs catalyst (f) before and (g) after 30,000 cycles of ORR support ADT. 


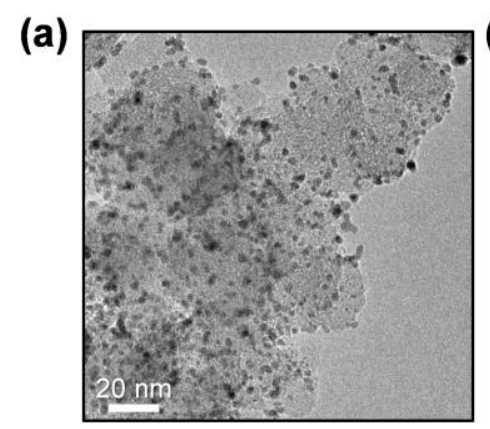

(b)

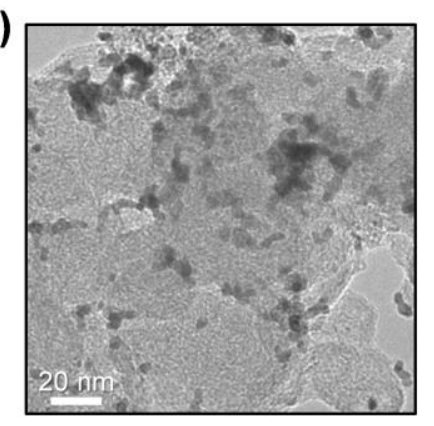

(c)
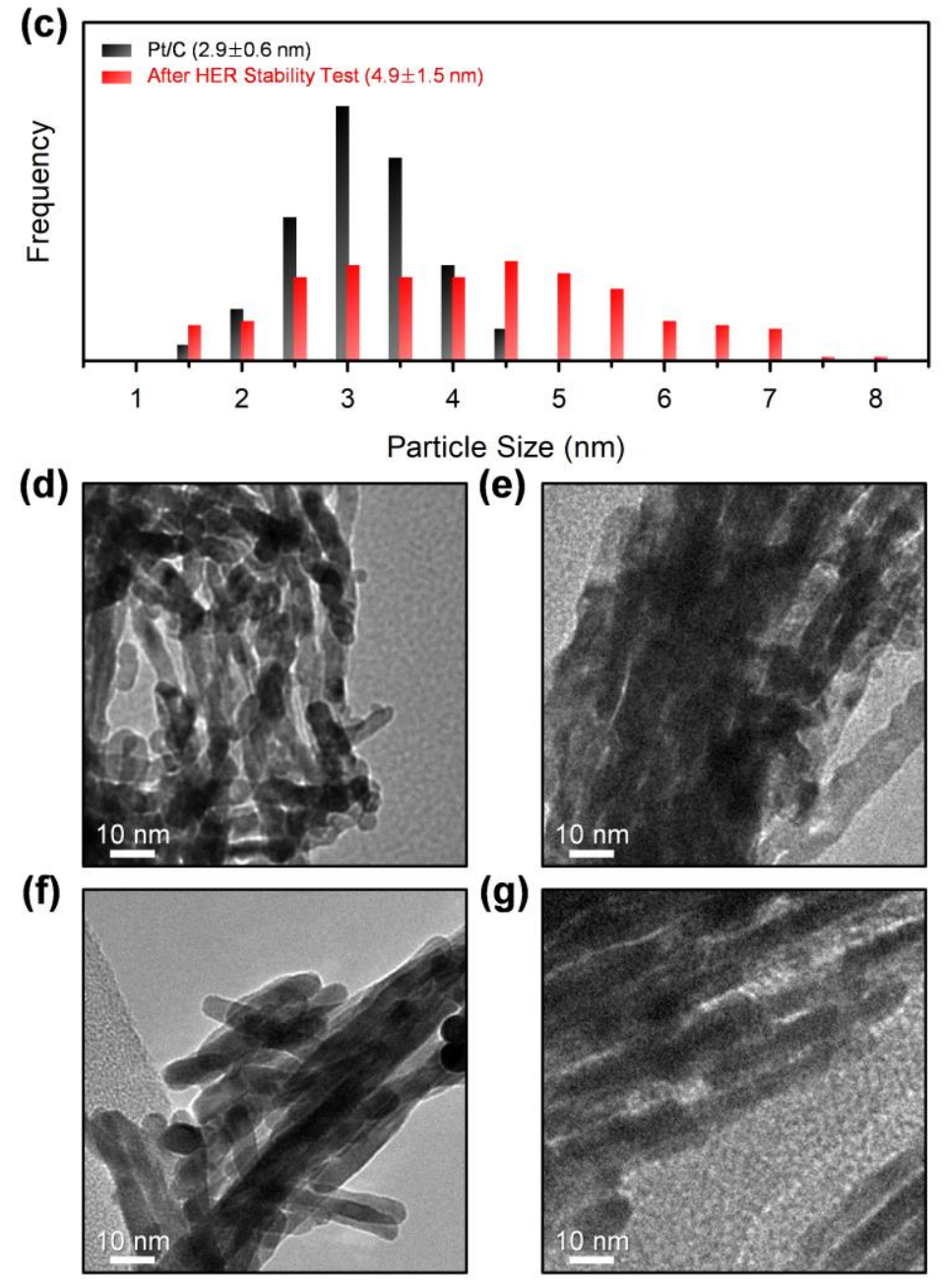

Figure S25. TEM analyses of the catalysts before and after the alkaline HER stability tests. (a, b) TEM images of Pt/C catalyst (a) before and (b) after the HER stability test performed by chronopotentiometry at $-10 \mathrm{~mA} \mathrm{~cm}^{-2}$. (c) Particle size distribution histograms of Pt nanoparticles in Pt/C before and after the HER stability test. (d, e) TEM images of $D$ - $\mathrm{Pt}_{3} \mathrm{Co}$ NWs catalyst (d) before and (e) after the HER stability test. (f, g) TEM images of $O$ - $\mathrm{Pt}_{3} \mathrm{Co}$ NWs catalyst (f) before and $(\mathrm{g})$ after the HER stability test. 

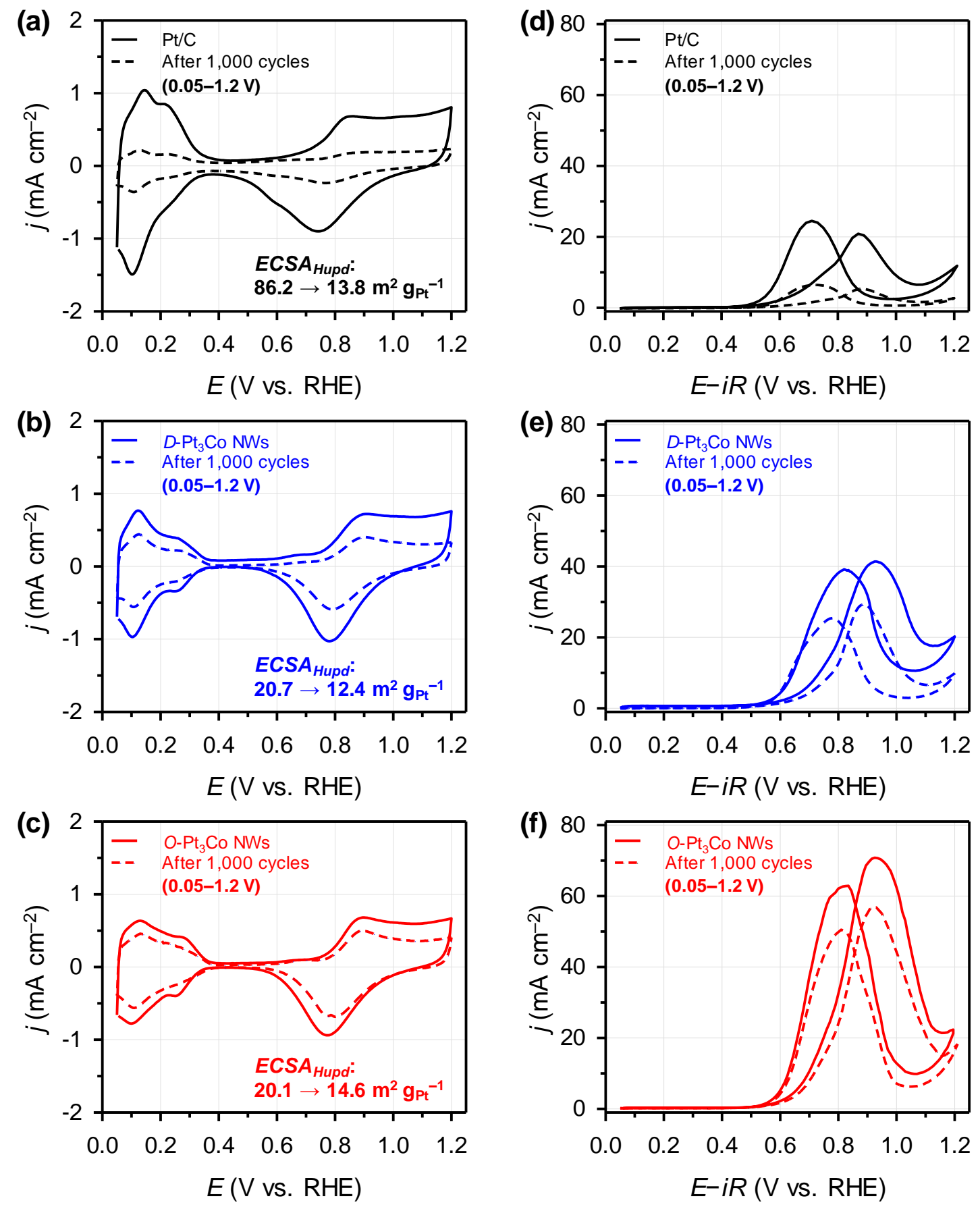

Figure S26. Electrocatalytic properties of the catalysts before and after the MOR ADT. (a-c) CVs in the range of $0.05-1.2 \mathrm{~V}$ and $(\mathrm{d}-\mathrm{f}) \mathrm{MOR} \mathrm{CVs}$ of $\mathrm{Pt} / \mathrm{C}(\mathrm{a}, \mathrm{d}), D-\mathrm{Pt}_{3} \mathrm{Co} \mathrm{NWs}(\mathrm{b}, \mathrm{e})$, and $O-\mathrm{Pt}_{3} \mathrm{Co}$ NWs $(\mathrm{c}, \mathrm{f})$ before and after 1,000 cycles of MOR ADT in the range of 1.0-1.5 V. 
(a)

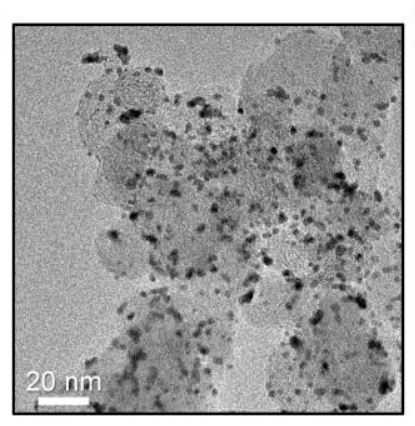

(c)

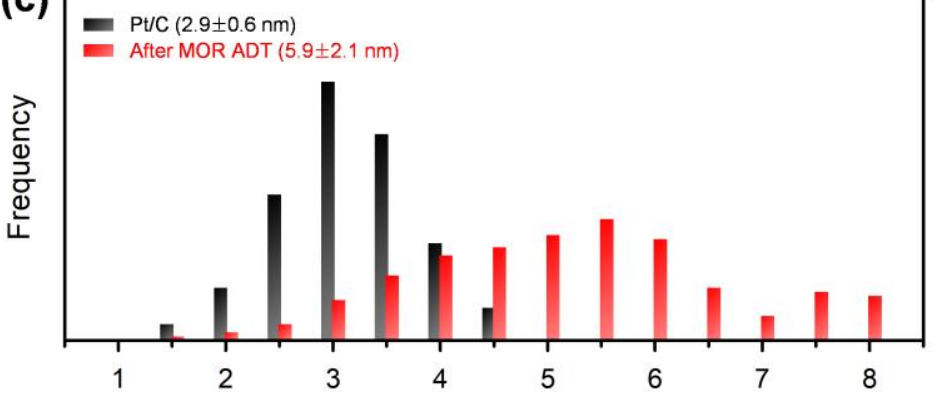

Particle Size $(\mathrm{nm})$

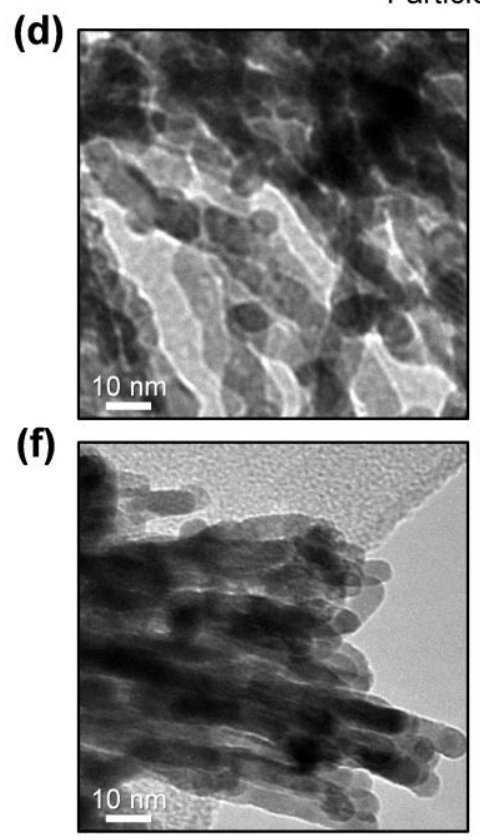

(b)

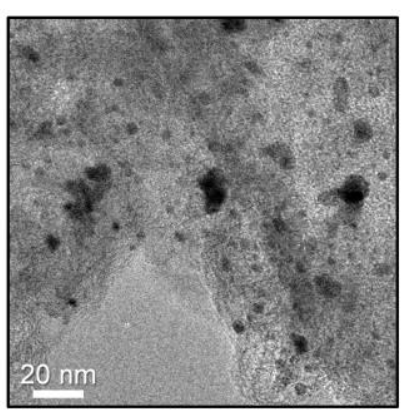

(e)

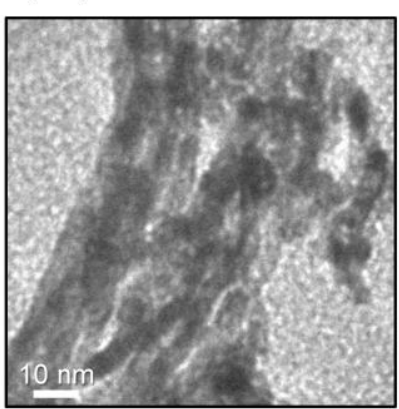

(g)

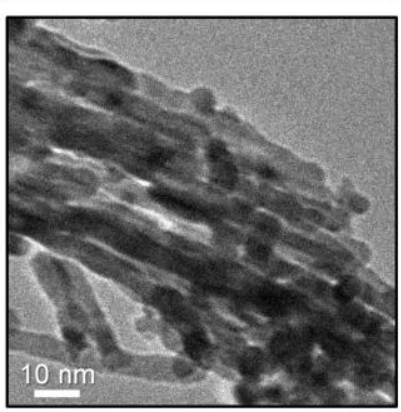

Figure S27. TEM analyses of the catalysts before and after the MOR ADT. (a, b) TEM images of $\mathrm{Pt} / \mathrm{C}$ catalyst (a) before and (b) after 1,000 cycles of MOR ADT in the range of 0.05-1.2 V. (c) Particle size distribution histograms of Pt nanoparticles in Pt/C before and after the MOR ADT. (d, e) TEM images of $D-\mathrm{Pt}_{3}$ Co NWs catalyst (d) before and (e) after the MOR ADT. (f, g) TEM images of $O-\mathrm{Pt}_{3} \mathrm{Co}$ NWs catalyst (f) before and (g) after the MOR ADT. 
(a)

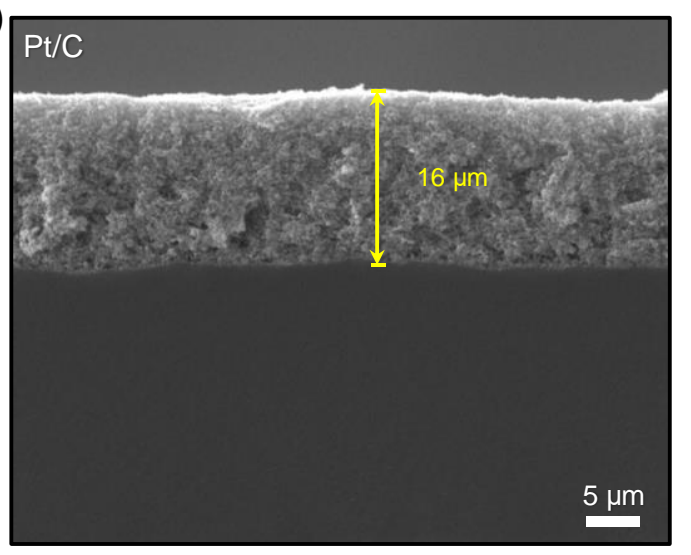

(b)

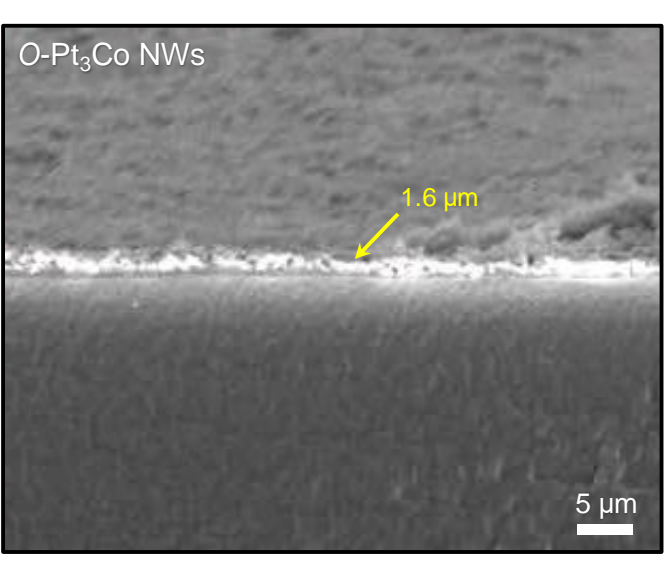

Figure S28. Cross-sectional SEM images of MEAs for PEMFC single cells. (a) Pt/C-based PEMFC. (b) $O-\mathrm{Pt}_{3} \mathrm{Co} \mathrm{NWs}$-based PEMFC. The thicknesses of the cathode catalyst layers are given in the images. 

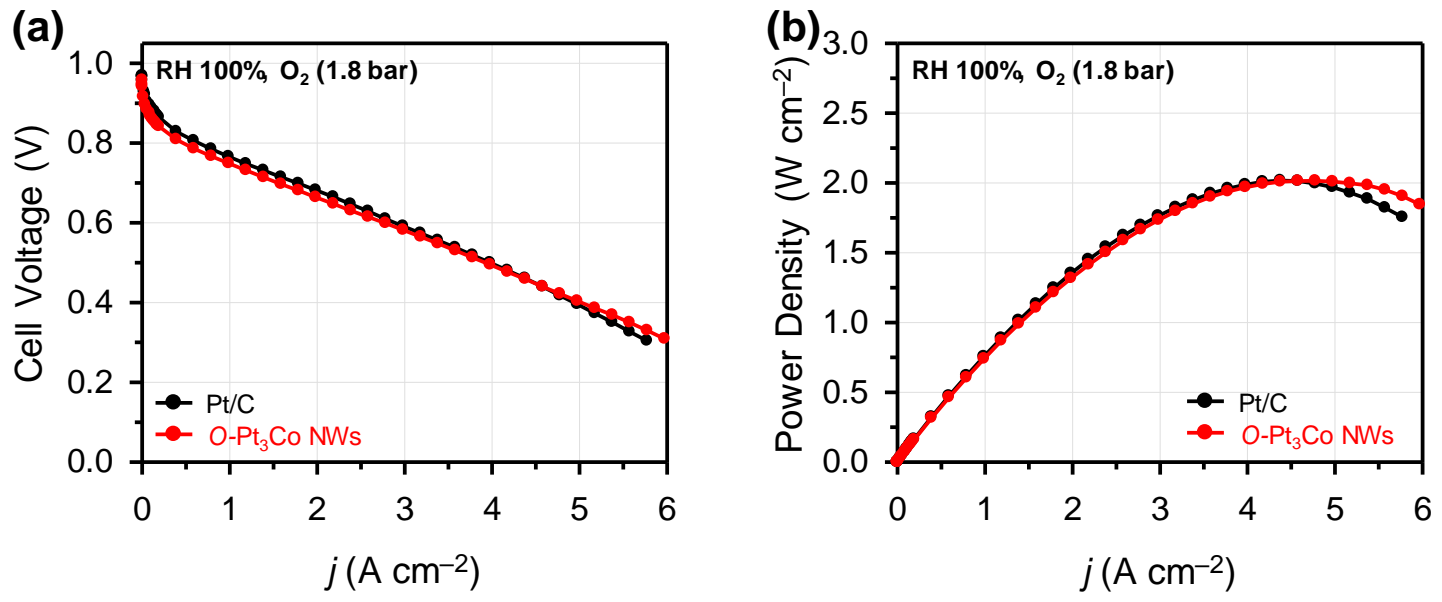

Figure S29. PEMFC single cell performances of MEAs tested in $\mathrm{RH} 100 \%, \mathrm{O}_{2} 1.8$ bar. (a) Polarization curves and (b) power density curves of $\mathrm{Pt} / \mathrm{C}$ - and $O$ - $\mathrm{Pt}_{3} \mathrm{Co}_{\mathrm{NW}} \mathrm{N}-$ based MEAs. 

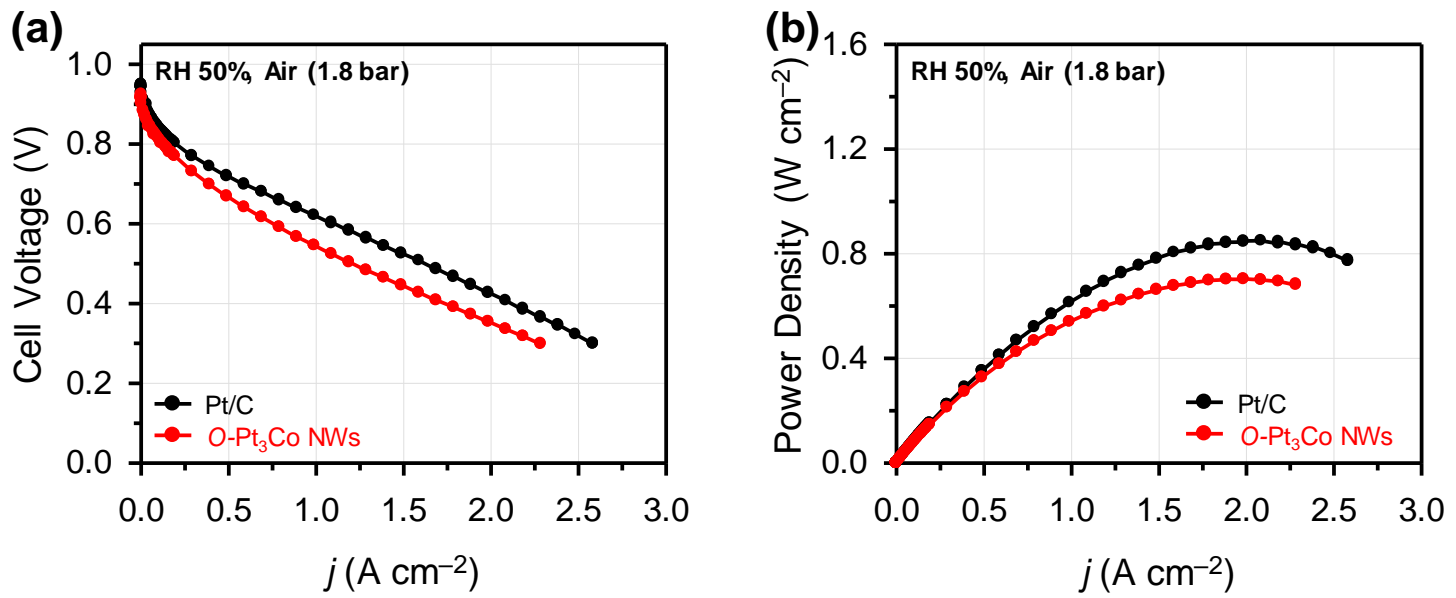

Figure S30. PEMFC single cell performances of MEAs tested in RH 50\%, air 1.8 bar. (a) Polarization curves and (b) power density curves of Pt/C- and $O$ - $\mathrm{Pt}_{3} \mathrm{Co}_{\mathrm{NW}} \mathrm{N}-$ based MEAs. 

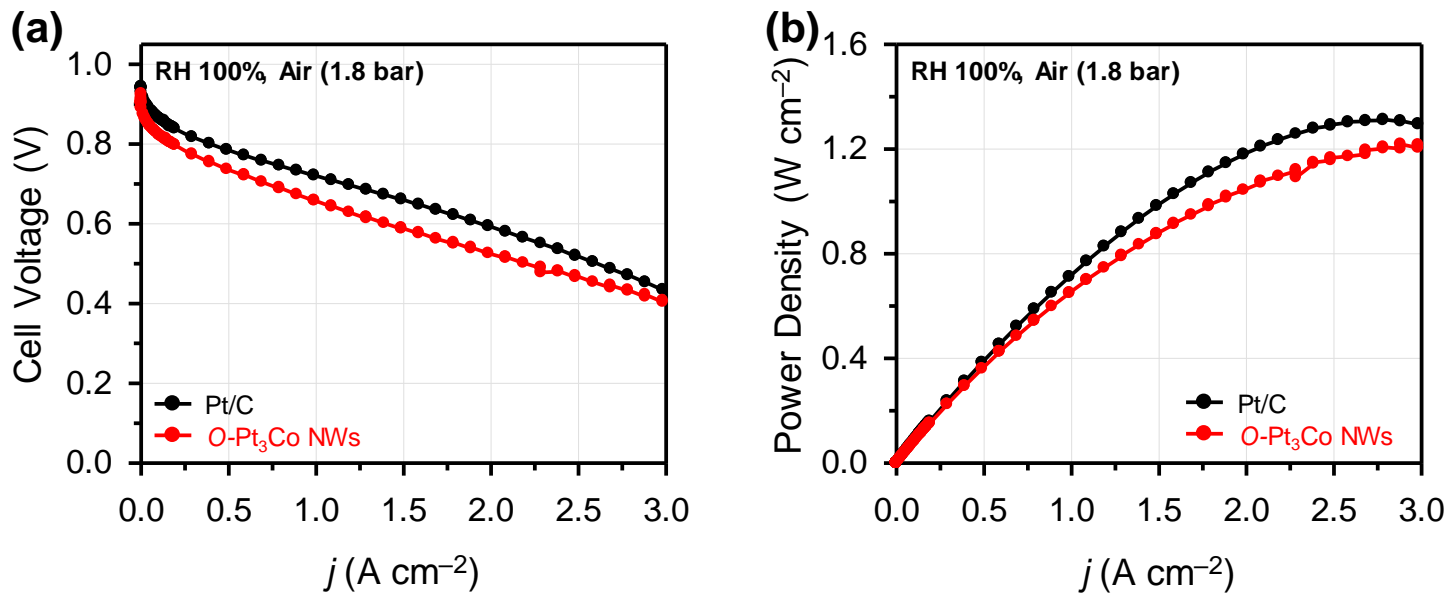

Figure S31. PEMFC single cell performances of MEAs tested in RH 100\%, air 1.8 bar. (a) Polarization curves and (b) power density curves of $\mathrm{Pt} / \mathrm{C}$ - and $O$-Pt ${ }_{3} \mathrm{Co}$ NWs-based MEAs. 
Table S1. Fitting results of the multiple linear regression model to predict DFT-calculated oxygen binding energies.

\begin{tabular}{|c|c|c|c|c|c|c|}
\hline & coefficient & & standard & & \multicolumn{2}{|c|}{$95 \%$ confidence interval } \\
\hline variables & $(\mathrm{eV})$ & $P$ value $^{a}$ & error & $\mathrm{t}^{a, b}$ & lower & upper \\
\hline$n_{\mathrm{CO}(\mathrm{e})}$ & 0.121 & $5.52 \times 10^{-4}$ & $7.66 \times 10^{-3}$ & 15.79 & 0.0966 & 0.1454 \\
\hline$n_{\mathrm{Co}(\mathrm{c})}$ & 0.019 & 0.163 & $1.03 \times 10^{-2}$ & 1.841 & -0.0138 & 0.0516 \\
\hline Intercept & 0.225 & $4.80 \times 10^{-4}$ & $1.36 \times 10^{-2}$ & 16.55 & 0.1818 & 0.2684 \\
\hline
\end{tabular}


Table S2. $\Delta E_{\mathrm{O}}$ values calculated using the linear regression model, the population of distinct subsurface-coordinating-environments, and estimated specific activity enhancement at all possible active sites of the $D-\mathrm{Pt}_{3} \mathrm{Co}$ surface. For comparison, $O-\mathrm{Pt}_{3} \mathrm{Co}$ cases are shown in parenthesis.

\begin{tabular}{|c|c|c|c|c|}
\hline$n_{\mathrm{Co}(\mathrm{c})}$ & $n_{\mathrm{Co}(\mathrm{e})}$ & $\begin{array}{c}\Delta E_{\mathrm{O}} \text { from } \\
\text { Linear Model } \\
(\mathrm{meV})\end{array}$ & $\begin{array}{l}\text { Population } \\
\text { (\%) }\end{array}$ & $\begin{array}{c}\text { Predicted SA } \\
\text { Enhancement } \\
\text { (Relative to Pt) }\end{array}$ \\
\hline \multirow{4}{*}{0} & 0 & 225 & 17.80 & 24.1836 \\
\hline & 1 & 244 & $\begin{array}{c}17.80 \\
\left(75 \text { for } O-\mathrm{Pt}_{3} \mathrm{Co}\right)\end{array}$ & 17.0061 \\
\hline & 2 & 263 & 5.93 & 11.9589 \\
\hline & 3 & 282 & 0.66 & 8.4096 \\
\hline \multirow{4}{*}{1} & 0 & 346 & 17.80 & 2.5458 \\
\hline & 1 & 365 & 17.80 & 1.7902 \\
\hline & 2 & 384 & 5.93 & 1.2589 \\
\hline & 3 & 403 & 0.66 & 0.8853 \\
\hline \multirow{4}{*}{2} & 0 & 467 & 5.93 & 0.2680 \\
\hline & 1 & 486 & 5.93 & 0.1885 \\
\hline & 2 & 505 & 1.98 & 0.1325 \\
\hline & 3 & 524 & 0.22 & 0.0932 \\
\hline \multirow{4}{*}{3} & 0 & 588 & $\begin{array}{c}0.66 \\
\left(25 \text { for } D-\mathrm{Pt}_{3} \mathrm{Co}\right)\end{array}$ & 0.0282 \\
\hline & 1 & 607 & 0.66 & 0.0198 \\
\hline & 2 & 626 & 0.22 & 0.0140 \\
\hline & 3 & 645 & 0.02 & 0.0098 \\
\hline$D-\mathrm{Pt}_{3} \mathrm{Co}$ & \multicolumn{3}{|c|}{$\Sigma\left\{\left(\right.\right.$ Population $\left._{\text {site }} ; \%\right) \times\left(\right.$ SA Enhancement $\left.\left._{\text {site }}\right)\right\}$} & 8.978 \\
\hline$O-\mathrm{Pt}_{3} \mathrm{Co}$ & \multicolumn{3}{|c|}{$75 \% \times 17.0061+25 \% \times 0.0282$} & 12.762 \\
\hline
\end{tabular}

${ }^{a}$ activity enhancement estimated from the ORR volcano plot at $\Delta E_{\mathrm{O}}$ by linear model. 
Table S3. Comparison of ORR activity parameters of $O-\mathrm{Pt}_{3} \mathrm{Co}$ NWs with those of previously reported Pt-based free-standing catalysts.

\begin{tabular}{|c|c|c|c|c|c|c|}
\hline catalyst & $\begin{array}{c}\text { loading } \\
\left(\mu \mathrm{g}_{\mathrm{Pt}} \mathrm{cm}^{-2}\right)\end{array}$ & $\begin{array}{l}E_{1 / 2} \\
(\mathrm{~V})^{a}\end{array}$ & $\begin{array}{l}E C S A_{\text {Hupd }} \\
\left(\mathrm{m}^{2} \mathrm{gPt}^{-1}\right)^{b}\end{array}$ & $\begin{array}{c}M A @ 0.9 \mathrm{~V} \\
\left(\mathrm{~A} \mathrm{mg}_{\mathrm{Pt}}^{-1}\right)^{c}\end{array}$ & $\begin{array}{l}S A @ 0.9 \mathrm{~V} \\
\left(\mathrm{~mA} \mathrm{cmPt}{ }^{-2}\right)^{d}\end{array}$ & ref. \\
\hline$O-\mathrm{Pt}_{3} \mathrm{Co} \mathrm{NWs}$ & 55 & 0.93 & 20.1 & 0.31 & 1.56 & $\begin{array}{l}\text { This } \\
\text { work }\end{array}$ \\
\hline PtPd NTs & 40 & 0.84 & 15.2 & $\begin{array}{c}0.11 \\
(@ 0.85 \mathrm{~V})\end{array}$ & $\begin{array}{c}0.78 \\
(@ 0.85 \mathrm{~V})\end{array}$ & (S1) \\
\hline $\begin{array}{l}\text { Double Gyroid } \\
\text { Pt Thin Film }\end{array}$ & 40 & 0.87 & 38.2 & 0.31 & 0.81 & (S2) \\
\hline $\begin{array}{c}\mathrm{Pt} \\
\text { Nanoassembly }\end{array}$ & 200 & 0.84 & 40.8 & $\begin{array}{c}0.11 \\
(@ 0.85 \mathrm{~V})\end{array}$ & $\begin{array}{c}0.26 \\
(@ 0.85 \mathrm{~V})\end{array}$ & (S3) \\
\hline PtPdCu NTs & 12 & 0.90 & 78.1 & 0.52 & 0.68 & (S4) \\
\hline $\begin{array}{c}\mathrm{Pt} \\
\text { Membranes }\end{array}$ & 200 & & 40.8 & 0.16 & 0.28 & (S5) \\
\hline $\begin{array}{l}\text { Mesoporous Pt } \\
\text { Nanospheres }\end{array}$ & 167 & 0.92 & 21.6 & 0.07 & 0.34 & (S6) \\
\hline $\begin{array}{c}\text { Pt-Pd } \\
\text { Nanoflowers }\end{array}$ & 51 & 0.80 & 18.6 & $\begin{array}{c}0.02 \\
(@ 0.85 \mathrm{~V})\end{array}$ & 0.08 & (S7) \\
\hline PtPd NWs & 5 & 0.88 & 50.0 & 0.81 & 0.40 & (S8) \\
\hline $\begin{array}{c}\text { Intermetallic } \\
\text { FePt NTs }\end{array}$ & 70 & 0.88 & 35.0 & 0.14 & 0.41 & (S9) \\
\hline $\begin{array}{c}\text { Pt } \\
\text { Skeletal NTs }\end{array}$ & - & 0.92 & 21.1 & 0.21 & 0.99 & $(\mathrm{~S} 10)$ \\
\hline Meso-PtNi_2 & 135 & 0.90 & 15.7 & 0.11 & 0.70 & (S11) \\
\hline $\begin{array}{c}\mathrm{NiPt} \\
\text { 2D Nanoframes }\end{array}$ & 35 & 0.92 & 5.3 & 0.23 & 5.8 & (S12) \\
\hline
\end{tabular}




\section{References}

(S1) Chen, Z.; Waje, M.; Li, W.; Yan, Y. Supportless Pt and PtPd Nanotubes as Electrocatalysts for Oxygen-Reduction Reactions. Angew. Chem. Int. Ed. 2007, 46, 4060-4063.

(S2) Kibsgaard, J.; Gorlin, Y.; Chen, Z.; Jaramillo, T. F. Meso-Structured Platinum Thin Films: Active and Stable Electrocatalysts for the Oxygen Reduction Reaction. J. Am. Chem. Soc. 2012, 56, 7758-7765.

(S3) Xia, B. Y.; Ng, W. T.; Wu, H. B.; Wang, X.; Lou, X. W. Self-Supported Interconnected Pt Nanoassemblies as Highly Stable Electrocatalysts for Low-Temperature Fuel Cells. Angew. Chem. Int. Ed. 2012, 51, 7213-7216.

(S4) Li, H.-H.; Cui, C.-H.; Zhao, S.; Yao, H.-B.; Gao, M.-R.; Fan, F.-J.; Yu, S.-H. Mixed-PtPdShell PtPdCu Nanoparticle Nanotubes Templated from Copper Nanowires as Efficient and Highly Durable Electrocatalysts. Adv. Energy Mater. 2012, 2, 1182-1187.

(S5) Xia, B. Y.; Wu, H. B.; Yan, Y.; Lou, X. W.; Wang, X. Ultrathin and Ultralong SingleCrystal Platinum Nanowire Assemblies with Highly Stable Electrocatalytic Activity. J. Am. Chem. Soc. 2013, 135, 9480-9485.

(S6) Chen, P.-K.; Lai, N.-C.; Ho, C.-H.; Hu, Y.-W.; Lee, J.-F.; Yang, C.-M. New Synthesis of MCM-48 Nanospheres and Facile Replication to Mesoporous Platinum Nanospheres as Highly Active Electrocatalysts for the Oxygen Reduction Reaction. Chem. Mater. 2013, 25, 4269-4277.

(S7) Fu, G.; Wu, K.; Lin, J.; Tang, Y.; Chen, Y.; Zhou, Y.; Lu, T. One-Pot Water-Based Synthesis of Pt-Pd Alloy Nanoflowers and Their Superior Electrocatalytic Activity for the Oxygen Reduction Reaction and Remarkable Methanol-Tolerant Ability in Acid Media. J. Phys. Chem. C 2013, 117, 9826-9834.

(S8) Li, H.-H.; Ma, S.-Y.; Fu, Q.-Q.; Liu, X.-J.; Wu, L.; Yu, S.-H. Scalable Bromide-Triggered Synthesis of Pd@Pt Core-Shell Ultrathin Nanowires with Enhanced Electrocatalytic Performance toward Oxygen Reduction Reaction. J. Am. Chem. Soc. 2015, 137, 7862-7868.

(S9) Lee, J.; Yoo, J. M.; Ye, Y.; Mun, Y.; Lee, S.; Kim, O.-H.; Rhee, H.-W.; Lee, H. I.; Sung, Y.-E.; Lee, J. Development of Highly Stable and Mass Transfer-Enhanced Cathode Catalysts: Support-Free Electrospun Intermetallic FePt Nanotubes for Polymer Electrolyte Membrane Fuel Cells. Adv. Energy Mater. 2015, 5, 1402093.

(S10) Wang, R.; Higgins, D. C.; Prabhudev, S.; Lee, D.U.; Choi, J.-Y.; Hoque, M. A.; Botton, G. A.; Chen, Z. Synthesis and Structural Evolution of Pt Nanotubular Skeletons: Revealing the Source of the Instability of Nanostructured Electrocatalysts. J. Mater. Chem. A 2015, 3, 1266312671.

(S11) Kim, H. Y.; Cho, S.; Sa, Y. J.; Hwang, S.-M.; Park, G.-G.; Shin, T. J.; Jeong, H. Y.; Yim, S.-D.; Joo, S. H. Self-Supported Mesostructured Pt-Based Bimetallic Nanospheres Containing an Intermetallic Phase as Ultrastable Oxygen Reduction Electrocatalysts. Small 2016, 12, 53475353.

(S12) Godínez-Salomón, F.; Mendoza-Cruz, R.; Arellano-Jimenez, M. J.; Jose-Yacaman, M.; Rhodes, C. P. Metallic Two-Dimensional Nanoframes: Unsupported Hierarchical NickelPlatinum Alloy Nanoarchitectures with Enhanced Electrochemical Oxygen Reduction Activity and Stability. ACS Appl. Mater. Interfaces 2017, 9, 18660-18764. 